
$\$$ Research Square
Preprints are preliminary reports that have not undergone peer review.
They should not be considered conclusive, used to inform clinical practice, or referenced by the media as validated information.

\title{
The effectiveness of interventions on nutrition social behaviour change communication in improving child nutritional status within the first 1000 days: Evidence from a systematic review and meta-analysis
}

Rashidul Alam Mahumud ( $\square$ md.mahumud@sydney.edu.au )

The University of Sydney https://orcid.org/0000-0001-9788-1868

Sophiya Uprety

UNICEF

Nidhi Wali

Western Sydney University

Andre M.N. Renzaho

Western Sydney University - Campbelltown Campus

Stanley Chitekwe

UNICEF Ethiopia

\section{Research Article}

Keywords: IYCF, Infant and Young Child Feeding, child nutrition, 1000 days, Nutrition Education, Nutrition Social Behaviour Change Communication, NSBCC, Nutrition BCC

Posted Date: June 21st, 2021

DOI: https://doi.org/10.21203/rs.3.rs-632869/v1

License: (c) (i) This work is licensed under a Creative Commons Attribution 4.0 International License. Read Full License

Version of Record: A version of this preprint was published at Maternal \& Child Nutrition on November 29th, 2021. See the published version at https://doi.org/10.1111/mcn.13286. 


\section{Abstract}

This systematic review and meta-analysis aimed to assess the robustness of designs and tools used in NSBCC interventions and establish their effectiveness. EBSCOhost as an umbrella database including Medline (Ovid) and CINAHL, EMBASE and ProQUEST databases were searched for peer-reviewed articles from January 1960 to October 2018. Additional sources were searched to identify all relevant studies including grey literature. Studies' biases were assessed according to Cochrane handbook. Pooled estimate of effectiveness of interventions on infant and young child feeding (IYCF) practices and child nutritional status with $95 \%$ confidence intervals were measured using random-effects models. Eighty studies were included in this review: Fifty-one (64\%) were cluster randomised trials (RCTs), 13 (16\%) were RCTs and $16(20 \%)$ quasi-experimental. Of the included studies, $22(27 \%)$ measured early initiation of breastfeeding, 38 (47\%) measured exclusive breastfeeding, 29 (36\%) measured minimum dietary diversity, 21 (26\%) measured minimum meal frequency, 26 (32\%) measured HAZ, 23 (29\%) measured WHZ, 27 (34\%) measured WAZ, 20 (25\%) measured stunting, 14 (17\%) measured wasting, and 11 (14\%) measured underweight. The overall intervention's effect was significant for $E B F(O R=1.73 ; 95 \% \mathrm{Cl}$ : $1.35-$ 2.11, $\mathrm{p}<0.001$ ), HAZ (Standardized Mean Differences, SMD = 0.19; 95\% Cl: 0.17-0.21; $<<0.001$ ), WHZ $(\mathrm{SMD}=0.02 ; 95 \% \mathrm{Cl}: 0.004$ to $0.04 ; \mathrm{p}<0.001)$, and $W A Z$ (SMD $=0.04 ; 95 \% \mathrm{Cl}: 0.02$ to $0.06 ; \mathrm{p}<0.001)$. Evidence shows the effectiveness of NSBCC in improving EBF and child anthropometric outcomes. Further research should test the impact on child nutritional status with clearly specified and detailed NSBCC interventions.

\section{Key Messages}

- The NSBCC interventions significantly improved EBF practices and child anthropometric outcomes and need to be considered while planning child nutrition interventions.

- Studies used different intervention protocols and operational definitions. Most studies employed a mix of the NSBCC interventions often with unspecified frequency and dosage.

- Future intervention studies should provide detailed implementation strategies for NSBCC interventions and use standard indicators to measure child nutritional status outcome indicators.

\section{Introduction}

Nutrition, a fundamental driver of Sustainable Development Goals (SDG), is crucial to achieve both nutrition specific and nutrition sensitive goals and targets (UNSCN, 2015). Child undernutrition rates have declined globally but still continue to be unacceptably high and disproportionately affect the low and middle-income countries (UN, 2015); de Onis et al., 2018; (Development Initiatives, 2018). Malnutrition in infancy is associated with impaired cognitive, physical, and metabolic functions, leading to poor mental development and school achievement and behavioural abnormalities (Martins et al., 2011). Child undernutrition increases the risk of cardiovascular diseases in adulthood (Victora et al., 2008). There is 
now tremendous opportunity to accelerate actions to improve child nutrition given the unprecedented and sustained global momentum for nutrition.

The UNICEF conceptual framework of malnutrition shows a wide range of determinants at immediate, underlying and basic levels (UNICEF, 2013) which are interrelated and crosscut across many sectors, making nutrition a multi-sector responsibility (Bhutta et al., 2013; Ruel \& Alderman, 2013). Nutrition education or nutrition social behaviour change communication (NSBCC) intervention are critical in addressing infant and young child feeding (IYCF) and child undernutrition outcomes. The NSBCC interventions combine elements of interpersonal communication, social change and community mobilization activities, mass media, and advocacy to support individuals, families, communities, institutions, and countries to adopt and maintain high-impact nutrition-related practices (SPRING, 2019). The 'first 1000 days of life,' for the child for the period from conception till two years of age, is considered particularly crucial for child development (Victora et al., 2008), and thus has been a particular focus of the NSBCC interventions.

Although previous studies including systematic reviews have identified effectiveness of the NSBCC interventions in improving nutritional status and IYCF practices among children under two years of age (Dachi Arikpo, Ededet Sewanu Edet, Moriam T. Chibuzor, Friday Odey, \& Deborah M. Caldwell, 2018; Caulfield, Huffman, \& Piwoz, 1999; Kathryn G. Dewey \& Seth Adu-Afarwuah, 2008; Matthew M. Graziose, Downs, O’Brien, \& Fanzo, 2018; S. Lamstein et al., 2014; Tina Sanghvi, Renata Seidel, Jean Baker, \& Ann Jimerson, 2017; Shi \& Zhang, 2010) ), important gaps exist in evidence. For instance, World Health Organization (WHO) defined eight core IYCF indicators in 2008 including early initiation of breastfeeding (EIBF), exclusive breastfeeding (EBF), continued breastfeeding, introduction of complementary food, minimum dietary diversity (MDD), minimum meal frequency (MMF), minimum acceptable diet, consumption of iron-rich or iron-fortified foods (WHO, 2008). However, even after the standard indicators were defined, there have been very limited systematic reviews and/or meta-analysis that use these core indicators to report the impact on the IYCF. Hence, the reported effectiveness on the IYCF outcomes has been varied and the results have been difficult to compare.

Previous systematic reviews with meta-analysis that looked at the impact of nutrition education and/or NSBCC on child growth have differed in terms of study designs, intervention dose and intensity, and reported anthropometric measures, leading to contradictory and/or inconclusive results: one reported a modest effect (K. G. Dewey \& S. Adu-Afarwuah, 2008), four reported a significant impact (A. W. Girard \& O. Olude, 2012; Imdad, Yakoob, \& Bhutta, 2011; Z. S. Lassi, J. K. Das, G. Zahid, A. Imdad, \& Z. A. Bhutta, 2013a; A. Panjwani \& R. Heidkamp, 2017), and two reported limited or no impact (D. Arikpo et al., 2018; E. Gresham, J. E. Byles, A. Bisquera, \& A. J. Hure, 2014). Additionally, not all systematic reviews have consistently assessed the robustness and quality of included studies (D. Arikpo et al., 2018; K. G. Dewey \& S. Adu-Afarwuah, 2008; M. M. Graziose et al., 2018), whilst others have excluded non peer-reviewed publications (S. Lamstein et al., 2014) ) and quasi-experimental studies (D. Arikpo et al., 2018) and limited their analyses to nutrition education and mass media intervention only (M. M. Graziose et al., 2018). These limitations do not allow for comparative analyses of the effectiveness of the NSBCC 
interventions and their approaches. Therefore, the aim of our study was to assess the robustness of the NSBCC intervention designs and their effectiveness on child nutrition indicators reflected in the SDG as well as the key IYCF indicators that are important for child nutritional outcomes. The NSBCC approaches employed by each study were also closely examined to understand what works for each outcome. We anticipate that our study findings will provide a comprehensive understanding on the impact of the NSBCC interventions and will inform policies and programmes.

\section{Methods And Materials}

This study was performed and reported in accordance with the Preferred Reporting Items for Systematic Reviews and Meta-Analyses (PRISMA) guidelines for systematic reviews (Moher, Liberati, Tetzlaff, \& Altman, 2009).

Search Strategy: EBSCOhost as an umbrella database for Medline (Ovid) and CINAHL as well as EMBASE and ProQUEST databases were searched for peer-reviewed articles covering the period from January 1960 to October 2018. The search strategy, as below, was used for all databases. Full search syntax is provided in Supplementary Material 1:

(“Pregnant and Lactating women” OR famil* OR communit* OR household*)

AND

(Nutrition education OR “Behavior Change communication)"

AND

("Child nutrition status" OR Stunt* OR Underweight* OR Wast* OR "Child Body Mass Index" OR "Child undernutrition" OR breastfe* OR "exclusive breastfeeding" OR "complementary feeding" OR "supplementary feeding" OR "diet diversity" OR "infant and young child feeding")

AND

("randomised control trial" OR "cluster randomised" OR "quasi experiment" OR "quasi-experiment")

Reference list of included studies were further screened to identify any additional relevant papers. Furthermore, references in other systematic reviews that specifically focused on nutrition education or behaviour change communication for complementary feeding in developing countries were also reviewed. The International Clinical Trial Registry Platform of World Health Organisation (WHO) was also searched. This includes all clinical trials conducted globally - bringing registered trial data from 15 national and regional clinical trial registries together combining data, offering access to data from more than 200,000 trials.

Internet searches were conducted in resources repository within the websites of 29 organisations: Action Against Hunger (ACF), Alive and Thrive, Bill and Melinda Gates Foundation, Center for Disease Control 
and Prevention (CDC), Children's Investment Fund Foundation (CIFF), Food and Agriculture Organisation (FAO), Food and Nutrition Technical Assistance, Global Alliance for Improved Nutrition, Helen Keller International (HKI), IFAD, International Food Policy Research Institute (IFPRI), International Atomic Agency, John Snow Inc. (JSI), MANOFF Group, MQSUN, Nutrition Innovation Lab (NIL), PATH, Renewed Efforts Against Child Hunger and undernutrition (REACH), Results for Development (R4D), Save the Children, SPRING, Scaling Up Nutrition (SUN), United Nations Children's Fund (UNICEF), UNHCR, URC-University Research Centre, World Bank, World Food Programme (WFP), World Health Organisation (WHO) and World Vision International (WVI).

Individuals and organisations working on nutrition in developing countries were contacted for any additional studies.

Inclusion and exclusion criteria: Studies were included if they met the following criteria: (i) original randomised controlled trials (RCTs), or cluster RCTs, or quasi experimental studies with a primary focus on or having at least one separate experimental arm that addresses NSBCC activities and/or nutrition education, with having child nutritional status and/or IYCF indicators as outcome variables among children under two years of age (or within the first 1000 days); (ii) peer reviewed papers and grey literature published in English language and available in full text; (iii) conducted in low and middle income countries (including both lower middle and upper middle income categories) based on the World Bank country classification by income level (World Bank, 2018).

Studies were excluded if: (i) they were not RCTs, cluster RCTs or quasi experimental studies; (ii) were reviews or study/review protocols; (iii) conducted in high income countries (World Bank, 2018); (iv) nutrition education or behaviour change component that primarily focused on the promotion or uptake of food supplementation or lipid-based nutrient supplementation or multiple micronutrient supplementation; (v) focused only on neonatal outcomes (with only exclusive breastfeeding outcomes as a possible indicator); (vi) focused on overweight/obesity and non-communicable diseases.

Study selection and data extraction: All retrieved studies were exported to Endnote libraries by two researchers. Titles and abstract were screened for relevance by the first and second author. Those deemed not relevant were excluded. Abstracts and full texts were then reviewed independently by first and second author for inclusion. Any discrepancies related to inclusion were resolved through discussion. The first author identified additional relevant studies from other sources which were reviewed by all authors and concurred for inclusion. A standard data extraction format was developed. The first author extracted data from all included studies. A random sub-sample of $40 \%$ of included articles were extracted by the second author to ensure accuracy and completeness of data extraction procedure.

\section{Data analysis:}

Study summary 
Findings have been synthesized to provide a narrative summary of study characteristics and study effectiveness. The analysis was iterative and involved continuously reading the included studies to familiarise with and re-check the content. Three broad categorisation of social behaviour change communication (SBCC) approaches and the sub-approaches or activities within each category recommended by Spring 2014 were adapted and used as follows: interpersonal communication (one-onone counseling, group education, support groups); use of media (mass media, community radio / video, local billboards, brochures, posters, flyers, newsletters, calendars, reminder cards, songs, drama, cooking demonstration and social media); and community/social mobilization (campaigns, events, celebrations, special days, rallies, issue groups) (S. Lamstein et al., 2014).

\section{Statistical Analysis}

A meta-analysis was performed to examine the effectiveness of nutritional interventions on IYCF practices (i.e., early initiation of breastfeeding, EIBF; exclusive breastfeeding, EBF; minimum dietary diversity, MDD), and their impacts on child growth (i.e., height for age z-scores, HAZ; weight for height zscores, WHZ; and weight for age Z-scores, WAZ). Dichotomous data were reported as odds ratios (ORs) or prevalence ratios (PR) with 95\% confidence interval (Cl) and continuous data as the standardized mean differences with $95 \% \mathrm{Cls}$. Data were pooled using a random-effects models, whereas the high heterogeneity was detected between studies (I-squared, $I^{2}>50 \%$ ) (Higgins \& Thompson, 2002), with a sensitivity analysis to examine the effects of outliers. Heterogeneity was identified through visual inspection of the forest plots and also considered the $\mathrm{I}^{2}$ statistic, which quantifies the heterogeneity of the data in studies contained. Furthermore, publication bias was assessed using the Begg's test (Begg \& Mazumdar, 1994) and Egger's test (Egger, Davey Smith, Schneider, \& Minder, 1997). Both of the tests are commonly used to measure the tendency for the effects estimated in small sample size studies to differ from those estimated in larger studies. The risk of publication bias was analysed in terms of EIBF, EBF, MDD, HAZ, WHZ, and WAZ. Subgroup and meta-regression analyses were employed to investigate the effectiveness of interventions on IYCF practices and child growths, where moderate or higher heterogeneity was reported (Knapp \& Hartung, 2003; Sharp S., 1998). Finally, a permutation test was performed based on Monte Carlo simulation by controlling the risk of spurious findings from metaregression (Higgins \& Thompson, 2004), wherein unadjusted and adjusted estimation procedures were also used to calculate probability values ( $\mathrm{p}$-values) in meta-regression. In a permutation test, the covariates were randomly reallocated to the outcomes for 1,000 times to adjust for multiple testing.

Assessment of risk of bias in included studies: 'Risk of bias' assessment tool of Cochrane Handbook for Systematic Reviews of Interventions was used to assess the risks of bias of all included studies (The Cochrane Public Health Group, 2011). It encompassed the following domains: random sequence generation; allocation concealment; blinding of participants and personnel; blinding of outcome assessment; incomplete outcome data; selective outcome reporting and adequate protection against contamination. Our assessment of risk of bias of the included studies also involved reviewing study protocols where available and previous papers if they were cross referenced for details on the study 
designs. The first author conducted risk of bias assessment for all studies and a sample of $10 \%$ of included articles was independently assessed by the second author.

\section{Results}

Search overview: Database search yielded 1,201 publications. After removing 289 duplicates, 834 abstracts were reviewed based on inclusion/exclusion criteria, of these, 63 papers were retained for full text review. Finally, 47 studies met our inclusion criteria. Thirty-one additional peer reviewed papers were identified from searching the reference lists of retained papers and through contacting individuals and organization. Two studies identified from the grey literature also met our inclusion criteria, giving a final sample of 80 papers for review. The PRISMA flowchart is provided in Figure 1.

$<$ Insert Figure 1 here>

Risk of bias in included studies: The summary of risk of bias of the included papers is given (Appendix Figure A1). The detailed 'risk of bias' assessment of each study is provided in Supplementary Material 2. Due to the nature of the NSBCC interventions, blinding of participants was reported to be difficult, with less than half of the RCTs and cluster randomised trials including some forms of blinding. This increased the risk of bias, especially for the self-reported outcome measures. More than three quarters of the included studies had low risk of attrition bias and retention rate was $80 \%$ or more in both intervention and control arms. Similarly, more than three quarters of the studies also accounted for losses to follow-up.

Study Characteristics: Fifty-one (64\%) studies were cluster randomised trials, 13 (16\%) were RCTs and 16 $(20 \%)$ were quasi-experimental with or without control groups. Thirty-eight (48 \%) studies were from Asia, 35 (44 \%) from Africa, 6 (8\%) from South America and one (1\%) from Europe (Belarus.) The highest number of the included studies were conducted in Bangladesh 14 (17\%) followed by India $9(11 \%)$ from Asia; and 4 (5\%) each in Malawi and Uganda from Africa. Majority of studies, 56 (70\%), were conducted in rural community setting. Around a third were conducted in various urban contexts: urban community, 10 (13\%); urban health center, 8 (10\%); and urban/peri-urban slum, $3(4 \%)$. The remaining $3(4 \%)$ studies were conducted in multi-country settings. Only $1(1 \%)$ conducted prior to 1999 met the inclusion criteria. Forty-six (58 \%) studies were conducted during the MDG period of 2000-2015, while the remaining 33 (41 \%) studies were conducted from 2016 onwards, i.e., during the SDG era. Detailed characteristics of each study is provided (Appendix Table A1-A2).

Intervention characteristics, their impacts on IYCF practices and the associated NSBCC approaches: We focused on four of the core IYCF indicators recommended by the WHO: early initiation of breastfeeding (EIBF), exclusive breastfeeding (EBF); minimum dietary diversity (MDD) and minimum meal frequency (MMF) as they were the most commonly reported ones across the included studies and also being the key ones from the programmatic point of view. Of the 80 included studies, $22(27 \%)$ reported on EIBF, 38 (47 \%) on EBF, 29 (36 \%) on MDD and 21 (26 \%) on MMF. Results of the meta-analysis and systematic review are presented below. A summary of the NSBCC approaches and their effect on the four standard 
IYCF outcomes by study designs are given (Appendix Table A1). The specific changes and effect sizes for the measured indicators by each included study are provided (Appendix Table A1).

\section{Early initiation of breastfeeding (EIBF)}

Out of the 22 studies reporting on EIBF, 14 (64\%) found a statistically significant positive impact. Among all included studies across all designs: none of the RCTs measured or reported on EIBF; 15 out of the 51 (29\%) cluster randomised trials measured and reported on EIBF, of which, seven (47\%) reported statistically a significant positive impact; (Ara et al., 2018; Bhandari et al., 2003; M. S. I. Engebretsen et al., 2014; Flax et al., 2014; Haider, Ashworth, Kabir, \& Huttly, 2000; Kim et al., 2018; Menon, Nguyen, Saha, Khaled, Kennedy, et al., 2016; Waiswa et al., 2015); and seven (47\%) did not report any significant effect (Lewycka et al., 2013; More et al., 2017; Nguyen et al., 2017; Nikièma et al., 2017; Penfold et al., 2014; Saville et al., 2018; Tomlinson et al., 2014). One cluster randomised controlled trial was a multicountry which found a significant positive effect in two countries (Burkina Faso and Uganda) while no significant effect in one country (South Africa) (M. S. I. Engebretsen et al., 2014). Seven out of 16 (44\%) quasi-experimental studies measured and reported on EIBF and of those seven studies, six (86\%) reported a statistically significant positive impact (Dougherty et al., 2018; Guldan et al., 2000; Kim et al., 2016; Kushwaha et al., 2014; Lamstein et al., 2018; Saggurti et al., 2018); and one did not find any significant effect (Singh et al., 2018).

Overall, almost two third of the studies reported a significant positive effect on EIBF. The studies were of varying durations ranging from less than six months to more than two years. However, the length of studies - whether short or long - seemed to have no association with the outcome effect. Some studies that reported positive impact had employed interpersonal counselling during home visits and/or group learning approaches at communities while others used varying combination of additional NSBCC elements including use of media (IEC materials, mass media) and community mobilization. However, some studies using the similar approach, and/or their combinations did not find any significant effect (Appendix Table A1). The forest plot for ElBF is shown in Figure 2 (A). The overall positive effects of interventions on EIBF was 1.21 times higher among mothers in intervention group compared to control mothers (OR $=1.21,95 \% \mathrm{Cl}: 0.94-1.48)$. Most of the studies found very little positive effects on EIBF, and some even had negative effects. However, the studies were moderate heterogeneous with respect to intervention ( $I$-squared, $I 2=66.7 \% ; p=0.001$ ), preventing analysis of trends among similar studies.

$<$ Insert Figure 2(A) here>

\section{Exclusive breastfeeding (EBF)}

Of the 38 studies reporting on EBF, 33 (87\%) found a statistically significant positive impact (Appendix Table A1). All studies across all study designs: six out of 13 (46\%) RCTs measured or reported on EBF and of these, five (83 \%) found a significant positive effect (Aidam, Perez-Escamilla, \& Lartey, 2005; Bortolini \& Vitolo, 2012; Leite, Puccini, Atalah, Alves Da Cunha, \& Machado, 2005; Unger et al., 2018; Vitolo, Bortolini, Feldens, \& Drachler Mde, 2005); and one RCT did not find any significant effect (Tahir \& 
Al-Sadat, 2013). Twenty-two out of the 51 (43\%) cluster randomised trials measured and reported on EBF and of these, 20 (91\%) reported a statistically significant positive impact (Ara et al., 2018; Arifeen et al., 2009; Bhandari et al., 2003; I. M. Engebretsen et al., 2014; Flax et al., 2014; Gabida et al., 2015; Greenland et al., 2016; Haider et al., 2000; Kang, Suh, Debele, Juon, \& Christian, 2017; Kim et al., 2018; Ingrid M. Le Roux, Rotheram-Borus, Stein, \& Tomlinson, 2014; Lewycka et al., 2013; Menon, Nguyen, Saha, Khaled, Kennedy, et al., 2016; More et al., 2017; Nguyen et al., 2017; Nikièma et al., 2017; Tomlinson et al., 2014; Tylleskar et al., 2011; Waiswa et al., 2015; White et al., 2016); and two (9 \%) did not find any significant effect (Nair et al., 2017; Saville et al., 2018). Ten out of 16 (62 \%) quasi-experimental studies measured and reported on EBF and of these 10 studies, eight (80\%) reported a statistically significant positive impact (Aristiati Susiloretni et al., 2013; Guldan et al., 2000; Kim et al., 2016; Kimani-Murage et al., 2016; Kushwaha et al., 2014; Lamstein et al., 2018; Saggurti et al., 2018; Younes et al., 2015); while two (20\%) did not report any significant effect (Brasington et al., 2016; Dougherty et al., 2018).

Overall, almost all of the studies reported a significant positive effect on EBF. Similar to EIBF, the length of the studies that reported EBF also varied from less than six months to more than two years and the duration seemed to have no association with outcome effect (Appendix Table A1). Some studies reporting positive impact employed interpersonal counselling during home visits and/or group learning approaches at communities while others used varying combination with additional NSBCC elements including use of media (IEC materials, mass media, phone messaging) and community mobilization. However, few studies using the same approach, and/or their combinations did not find significant effect. Nineteen studies measured and reported on both EIBF and EBF, five of which found impact on EBF but not on EIBF (Lewycka et al., 2013; More et al., 2017; Nguyen et al., 2017; Nikièma et al., 2017; Tomlinson et al., 2014) while 12 found impact on both (Ara et al., 2018; Bhandari et al., 2003; Flax et al., 2014; Guldan et al., 2000; Haider et al., 2000; Kim et al., 2018; Kim et al., 2016; Kushwaha et al., 2014; Lamstein et al., 2018; Menon, Nguyen, Saha, Khaled, Kennedy, et al., 2016; Saggurti et al., 2018; Waiswa et al., 2015); one documented impact on EIBF but not on EBF (Dougherty et al., 2018) and one that had no impact on both (Saville et al., 2018). It appears that between the two standard indicators of breastfeeding, the NSBCC was likely to have more positive impact on EBF.

The overall effects of interventions on EBF is reported in forest plot (Figure 2(B)). The meta-analysis found that NSBCC interventions on EBF led to significant improvement among mothers in intervention group (IG) compared with controls $(\mathrm{OR}=1.73 ; 95 \% \mathrm{Cl}$ : 1.35-2.11, $\mathrm{p}<0.001)$. Heterogeneity was present in this analysis $(12=90.1 \%, p<0.001)$, however, $\mathrm{Cl}$ of some of the studies overlap to some degree.

$<$ Insert Figure 2(B) here $>$

\section{Minimum dietary diversity (MDD)}

Of the 29 studies reporting on MDD, 23 (79\%) found a statistically significant positive impact (Appendix Table A1). All studies across all study designs: one of the RCTs measured and reported a significant positive effect on MDD (Negash et al., 2014); 21 out of the 51 (41\%) cluster randomised trials measured and reported on MDD and of these, 16 (76\%) reported a statistically significant positive impact (Aboud \& 
Akhter, 2011; Aboud, Singla, Nahil, \& Borisova, 2013; Gelli et al., 2018; Jannat et al., 2018; Kang et al., 2017; Kim et al., 2018; Kuchenbecker, Reinbott, Mtimuni, Krawinkel, \& Jordan, 2017; Menon, Nguyen, Saha, Khaled, Sanghvi, et al., 2016; More et al., 2017; Nair et al., 2017; Nikièma et al., 2017; Rawat et al., 2017; Shi, Zhang, Wang, Caulfield, \& Guyer, 2010; Waswa, Jordan, Herrmann, Krawinkel, \& Keding, 2015; White et al., 2016; Zhang, Shi, Chen, Wang, \& Wang, 2013); and five (24 \%) did not report any significant effect (Byrd et al., 2018; Campbell et al., 2016; Olney, Pedehombga, Ruel, \& Dillon, 2015; Rockers et al., 2018; Saville et al., 2018). Seven out of the 16 (44\%) quasi-experimental studies measured and reported on MDD and of them, six ( $86 \%$ ) reported a statistically significant positive impact (Kilaru, Griffiths, Ganapathy, \& Ghosh, 2005; Kim et al., 2016; Lamstein et al., 2018; Mukuria, Martin, Egondi, Bingham, \& Thuita, 2016; Pachon et al., 2002; Singh et al., 2018).

Overall, more than two thirds of the studies reported a significant positive effect on MDD. Duration of the interventions on MDD varied from less than six months to more than two years does not seem to be strongly associated with positive or no effect. The NSBCC tools and/or approaches employed were interpersonal counselling and/or group learning sessions or in combination with use of media (IEC materials, cooking demonstration promoting locally available foods, mass media) and community mobilisation. Few studies employing similar approaches however did not find any significant impact. The overall effects of interventions related to NSBCC found a positive effect on MDD (prevalence ratio, PR = 1.17; $95 \% \mathrm{Cl}$ : 0.61-1.73) (Figure 2(C)), however, this association was not statistically significant.

$<$ Insert Figure 2(C) in here>

\section{Minimum meal frequency (MMF)}

Of the 21 studies reporting on MMF, 17 (81\%) reported a statistically significant positive impact (Appendix Table A1). All studies across all study designs: one RCT measured and reported a significant positive effect on MMF (Negash et al., 2014); sixteen out of the 51 (31\%) cluster randomised trials measured and reported on MMF and of these $12(75 \%)$ reported a statistically significant positive impact (Arifeen et al., 2009; Bhandari et al., 2004; Jannat et al., 2018; Kuchenbecker et al., 2017; Menon, Nguyen, Saha, Khaled, Sanghvi, et al., 2016; Nair et al., 2017; Nikièma et al., 2017; Roy et al., 2005; Roy et al., 2007; Shi et al., 2010; Waswa et al., 2015; Zhang et al., 2013); and four did not report any significant impact (Byrd et al., 2018; Kim et al., 2018; More et al., 2017; Rawat et al., 2017). Four out of the 16 (25\%) quasi-experimental studies measured and reported on MMF and all of them (100\%) reported a statistically significant positive impact (Kilaru et al., 2005; Kim et al., 2016; Lamstein et al., 2018; Mukuria et al., 2016).

Overall, more than two thirds of the studies reported a significant positive effect on MMF too. Similar to $M D D$, the duration of intervention seemed to vary from less than six months to more than two years. However, the length of studies - whether short or long - seemed to have no association with the outcome effect. The NSBCC tools and/or approaches employed were interpersonal counselling and/or group learning sessions or in combination with use of media (IEC materials, cooking demonstration promoting locally available foods, mass media) and community mobilization activities. Few studies 
employing similar approaches however did not find any significant impact on MMF. The overall effects of interventions on MMF (prevalence ratio, PR $=2.62 ; 95 \% \mathrm{Cl}$ : 0.80-4.45) (Figure 2(D)), however, this association was not statistically significant.

$<$ Insert Figure 2(D) here>

Minimum dietary diversity (MDD) and Minimum meal frequency (MMF)

Fourteen out of the 80 (17\%) studies measured both MDD and MMF (Byrd et al., 2018; Jannat et al., 2018; Kilaru et al., 2005; Kim et al., 2018; Kim et al., 2016; Kuchenbecker et al., 2017; Lamstein et al., 2018; Menon, Nguyen, Saha, Khaled, Sanghvi, et al., 2016; Mukuria et al., 2016; Nair et al., 2017; Negash et al., 2014; Nikièma et al., 2017; Waswa et al., 2015; Zhang et al., 2013). Out of these, 12 (86 \%) found a significant positive impact on both MDD and MMF (Jannat et al., 2018; Kilaru et al., 2005; Kim et al., 2016; Kuchenbecker et al., 2017; Lamstein et al., 2018; Menon, Nguyen, Saha, Khaled, Sanghvi, et al., 2016; Mukuria et al., 2016; Nair et al., 2017; Negash et al., 2014; Nikièma et al., 2017; Waswa et al., 2015; Zhang et al., 2013); while one study found a significant positive impact only on MDD (Kim et al., 2018); there were none that had significant positive impact only on MMF and one study did not have any significant impact on both. (Byrd et al., 2018). It appears that the NSBCC is equally likely to have significant positive effects on both MDD and MMF.

Intervention characteristics, their impacts on child nutritional status and the associated NSBCC tools: Our study focused on six standard indicators of child nutritional status among children less than two years of age (stunting, wasting, underweight, LAZ/HAZ (referred as only HAZ from here onward), WLZ/WHZ (referred only as WHZ from here onward) and WAZ (Appendix Table A2). Of the 80 included studies, 26 (32\%) reported on HAZ, 23 (29\%) reported on WHZ score, 27 (34\%) reported on WAZ, 20 (25\%) reported on stunting, $14(17 \%)$ reported on wasting and $11(14 \%)$ reported on underweight. Results of the metaanalysis (conducted for HAZ, WHZ and WAZ) and systematic review are presented below. A summary of their impact by study designs and the associated NSBCC tools are presented in Appendix Table A2. The specific changes and effect sizes for the measured indicators by each included study are given in Appendix Table A2.

Height for age $z$-scores (HAZ)

Of the 26 studies that reported on HAZ, nine (35\%) found a statistically significant positive impact. All studies across the study designs: two out of the $13(15 \%)$ RCTs measured or reported on HAZ and both did not find any significant positive impact (Santos et al., 2001; Seetha et al., 2018); 22 out of the 51 (43 $\%$ ) cluster randomised trials measured and reported on HAZ and of these 22 studies, seven (32\%) reported a statistically significant positive impact (Gelli et al., 2018; Marquis et al., 2018; Penny, CreedKanashiro, Robert, Narro, \& et al., 2005; Roy et al., 2007; Ruel et al., 2008; Tomlinson et al., 2014; Vazir et al., 2013); and 14 did not report any significant effect (Aboud et al., 2013; Arifeen et al., 2009; Bhandari et al., 2004; I. M. Engebretsen et al., 2014; Kuchenbecker et al., 2017; Menon, Nguyen, Saha, Khaled, Sanghvi, et al., 2016; Muhoozi et al., 2018; Nair et al., 2017; Rockers et al., 2018; Saville et al., 2018; Singla, 
Kumbakumba, \& Aboud, 2015; Waswa et al., 2015; Zaman, Ashraf, \& Martines, 2008; Zhang et al., 2013); and one reported a significant negative effect (Fadnes et al., 2016). Two out of the 16 (12\%) quasiexperimental studies measured and reported on HAZ and both (100\%) reported a statistically significant positive impact (Guldan et al., 2000; Schroeder et al., 2002).

Overall, more than one third of the studies reported a significant positive impact on HAZ. There is no evidence of significant positive effect from RCTs, around a third of the cluster randomised trials reported a significant positive effect while the significant positive effect from quasi-experimental studies was based on two studies only. Most of the studies reporting a significant positive effect were conducted for a period of six months to one year while most of the longer duration studies did not report any significant effect and study duration of less than six month either did not report any impact or reported a negative impact. The studies reporting a significant positive effects on HAZ used interpersonal counselling and/or group learning sessions or in combination with other tools such as use of media (IEC materials, cooking demonstration promoting locally available foods, mass media) and community mobilization activities. However, studies that did not find any impact also employed same or similar approaches. Hence, it is difficult to associate any particular NSBCC tool or approach with improvement in HAZ.

The meta-analysis showed that the overall effectiveness of NSBCC on HAZ in terms of z-scores increased significantly among child in intervention group (Standardized Mean Differences, SMD $=0.19 ; 95 \% \mathrm{Cl}$ : $0.17-0.21 ; p<0.001)$ compared with control (Figure $3(A)$ ). A considerable heterogeneity was present in this analysis $\left(I^{2}=99.5 \%\right)$.

$<$ Insert Figure 3(A) here>

Weight for height $z$-scores (WHZ)

Of the 23 studies that reported WHZ, six (26\%) found a statistically significant positive impact (Appendix Table A2). All studies across the study designs: two out of the 13 (15\%) RCTs measured or reported on WHZ and among them, one reported a significant positive impact (Seetha et al., 2018) while another did not find any significant impact (Santos et al., 2001). Nineteen out of the 51 (37\%) cluster randomised trials measured and reported on WHZ and of these 19 studies, four (21\%) reported a statistically significant positive impact (Penny et al., 2005; Ruel et al., 2008; Zaman et al., 2008; Zhang et al., 2013). One multi-country randomised controlled trial documented a positive impact in one country (South Africa) but a statistically significant negative impact in two countries (Burkina Faso and Uganda) (I. M. Engebretsen et al., 2014). Fourteen out of 19 studies (74 \%) did not report any significant positive impact (Arifeen et al., 2009; Gelli et al., 2018; Kuchenbecker et al., 2017; Ingrid M. Le Roux et al., 2014; Marquis et al., 2018; Menon, Nguyen, Saha, Khaled, Sanghvi, et al., 2016; Muhoozi et al., 2018; Nair et al., 2017; Nikièma et al., 2017; Roy et al., 2007; Saville et al., 2018; Tomlinson et al., 2014; Vazir et al., 2013; Waswa et al., 2015). Two out of the 16 (12\%) quasi-experimental studies measured and reported on WHZ and both (100\%) did not report any significant impact (Guldan et al., 2000; Schroeder et al., 2002). 
Overall, less than a third of studies reported a significant positive effect on WHZ while the majority of the included studies did not find any significant positive impact, across the three study designs. Duration of the intervention does not seem to have much association with any significant effects on WHZ also. The studies reporting significant positive effects on WHZ used interpersonal counselling and/or group learning sessions or in combination with use of media (IEC materials, cooking demonstration promoting locally available foods, mass media) and community mobilization activities. Most studies reporting significant positive effect included cooking demonstration promoting local foods. However, majority of studies that did not find any impact had also employed same or similar approaches. Hence, it is difficult to strongly associate any particular NSBCC tool or approach with improvement in WHZ.

The meta-analysis showed that the overall effects of interventions on WHZ was slightly increased (SMD $=0.02 ; 95 \% \mathrm{Cl}$ : 0.001 to $0.04 ; \mathrm{p}<0.001$ ) (Figure. $3(\mathrm{~B})$ ), whereas a considerable heterogeneity was noticed among these studies $\left(I^{2}=94.7 \%\right)$.

$<$ Insert Figure. 3(B) here>

Height for age z-scores (HAZ) and Weight for height z-scores (WHZ)

Twenty-two out of $80(27 \%)$ studies measured both HAZ and WHZ (Appendix Table A2). Out of the 22 studies, two (9 \%) found a significant positive effect on both HAZ and WHZ (Penny et al., 2005; Ruel et al., 2008); seven (32\%) found a positive impact only on HAZ (Gelli et al., 2018; Guldan et al., 2000; Marquis et al., 2018; Roy et al., 2007; Schroeder et al., 2002; Tomlinson et al., 2014; Vazir et al., 2013); three (14\%) had a positive impact WHZ only (Seetha et al., 2018; Zaman et al., 2008; Zhang et al., 2013); eight (36 \%) did not have positive impact on both (Arifeen et al., 2009; Kuchenbecker et al., 2017; Menon, Nguyen, Saha, Khaled, Sanghvi, et al., 2016; Muhoozi et al., 2018; Nair et al., 2017; Santos et al., 2001; Saville et al., 2018; Waswa et al., 2015); a multi-country study had a negative impact on WLZ in two countries (Burkina Faso and Uganda) and positive impact on one country (South Africa), while no impact on LAZ in all three countries (I. M. Engebretsen et al., 2014); and one study reported a significant negative impact on HAZ but a significant positive impact on WHZ (Fadnes et al., 2016).

Weight for age z-scores (WAZ)

Of the 27 studies that reported WAZ, 14 (52\%) found a statistically significant positive impact (Appendix Table A2). All studies across the study designs: five out of the 13 (38\%) RCTs measured or reported on WAZ and among these, three (60\%) reported a significant positive impact (Brown et al., 1992; I. M. le Roux et al., 2011; Seetha et al., 2018); one reported no significant impact (Santos et al., 2001) while one reported a significant negative impact (Jakobsen, Sodemann, Biai, Nielsen, \& Aaby, 2008). Twenty out of the 51 (39\%) cluster randomised trials measured and reported on WAZ and of them, nine (45\%) reported a statistically significant positive impact (Marquis et al., 2018; Penny et al., 2005; Roy et al., 2005; Roy et al., 2007; Ruel et al., 2008; Waswa et al., 2015; Zaman et al., 2008; Zhang et al., 2013); and nine (45\%) did not report any significant effect (Bhandari et al., 2004; Gelli et al., 2018; Kuchenbecker et al., 2017; Ingrid M. Le Roux et al., 2014; Menon, Nguyen, Saha, Khaled, Sanghvi, et al., 2016; Muhoozi et al., 2018; Nair et 
al., 2017; Saville et al., 2018; Vazir et al., 2013); while one multi-country study documented no significant impact in two countries (Burkina Faso and South Africa) but a statistically significant negative impact in one country (Uganda) (I. M. Engebretsen et al., 2014); and one study reported a significant negative impact (Fadnes et al., 2016). Two out of the 16 (12\%) quasi-experimental studies measured and reported on WAZ and both reported a statistically significant positive impact (Guldan et al., 2000; Schroeder et al., 2002).

Consistent with the overall effects of intervention, a tendency toward a increase in WAZ (SMD $=0.04 ; 95 \%$ Cl: 0.02 to $0.06 ; p<0.001)$ (Figure $3(C)$ ). Our analysis showed that a high heterogeneity $\left(I^{2}>75 \%\right)$ was also observed for meta-analysis (97\%) in terms of WAZ.

$<$ Insert Figure 3(C) here>

\section{Stunting}

Of the 20 studies that reported stunting, seven (35\%) found a statistically significant positive impact (Appendix Table A2). Among all included studies across the study designs: one (8\%) of the 13 RCTs had measured and reported on stunting and it did not find any significant impact (Bhandari et al., 2001); 17 out of $51(33 \%)$ of the cluster randomised trials had measured or reported on stunting and of those 17 studies, six (35\%) reported a significant positive impact (Gelli et al., 2018; Penny et al., 2005; Rockers et al., 2018; Ruel et al., 2008; Saleem, Mahmud, Baig-Ansari, \& Zaidi, 2014; Zhang et al., 2013); nine (53 \%) did not report any significant effect (Aboud et al., 2013; Arifeen et al., 2009; Bhandari et al., 2003; I. M. Engebretsen et al., 2014; Menon, Nguyen, Saha, Khaled, Sanghvi, et al., 2016; Nair et al., 2017; Nikièma et al., 2017; Olney et al., 2015; Saville et al., 2018); and two (12\%) reported a significant negative effect (Fadnes et al., 2016; Waswa et al., 2015). Out of 16, two (12\%) of the quasi-experimental studies reported on stunting and one ongoing study reported a positive effect as its midline finding (Sherburne, Math, Griffiths, Sacci, \& O’Donnell, 2018) while one did not find any significant effect (Schroeder et al., 2002).

Overall, around a third of the studies reported a significant positive impact on stunting. There is no evidence of a positive significant effect from the RCTs, only around a third of the cluster randomised trials have reported the positive evidence and the significant positive effect from quasi-experimental studies was based on one study only. Most of the studies reporting a significant positive effect were conducted for a period of six months to one year while most of the longer studies did not report any significant effect and study duration of less than six month either did not report any impact or reported a significant negative impact. The studies reporting a significant positive effects on stunting had used interpersonal counselling and/or group learning sessions or in combination with use of media (IEC materials, cooking demonstration promoting locally available foods and mass media). However, studies that did not find any impact had also employed same or similar approaches. Hence, it is difficult to associate any particular NSBCC tool or approach with improvement in stunting.

Wasting

Page 14/37 
Of the 14 studies that reported wasting, four $(29 \%)$ found a statistically significant positive effect (Appendix Table A2). Among all included studies across the study designs: only one of the 13 RCTs measured and reported on wasting and it did not find any significant impact (Bhandari et al., 2001). Twelve out of the 51 (23\%) cluster randomised trials measured or reported on wasting and of those 12 studies, three (25\%) reported a significant positive impact (Olney et al., 2015; Ruel et al., 2008; Saleem et al., 2014); and eight (61 \%) did not find any significant impact (Arifeen et al., 2009; Bhandari et al., 2003; Gelli et al., 2018; Menon, Nguyen, Saha, Khaled, Sanghvi, et al., 2016; Nair et al., 2017; Nikièma et al., 2017; Saville et al., 2018; Waswa et al., 2015). One multi-country cluster randomised trial documented no significant effect in two countries (Burkina Faso and South Africa) while a statistically significant negative impact in one country (Uganda) (I. M. Engebretsen et al., 2014). One out of the 16 (6\%) quasiexperimental studies measured and reported on wasting and it did not find any significant impact (Schroeder et al., 2002).

Overall, less than one third of the studies found a significant positive impact on wasting. There is no evidence of significant positive effect from the RCTs, around a third of the cluster randomised trials have reported significant positive effect and none from the quasi-experimental studies. Duration of intervention varied between less than a year to more than two years which does not seem to have an association with the effect on wasting. The studies reporting a significant positive effect on wasting had used interpersonal counselling and/or group learning sessions or in combination with media (IEC materials, cooking demonstration promoting locally available foods) and community mobilisation. However, studies that did not find any impact had also employed same or similar approaches. Hence, it is difficult to associate any particular NSBCC tool or approach with improvement in wasting.

\section{Stunting and Wasting}

Fourteen out of 80 (19\%) studies measured both stunting and wasting (Appendix Table A2). Out of these, two (11\%) found a significant positive impact on both (Ruel et al., 2008; Saleem et al., 2014); and one found a significant positive impact only on stunting (Gelli et al., 2018); one had a significant positive impact only on wasting (Olney et al., 2015); one multi-country study had no impact on stunting in all three countries and no impact on wasting in two countries (Burkina Faso and South Africa) while a significant negative impact on wasting in one country (Uganda) (I. M. Engebretsen et al., 2014); one study found a significant negative impact on stunting and no impact on wasting (Waswa et al., 2015); seven (50 \%) of the studies did not have any significant effect on both (Arifeen et al., 2009; Bhandari et al., 2003; Bhandari et al., 2001; Menon, Nguyen, Saha, Khaled, Sanghvi, et al., 2016; Nair et al., 2017; Nikièma et al., 2017; Saville et al., 2018; Schroeder et al., 2002). Of the eight studies that measured and reported on both IYCF practices and one or more indicators of growth, seven studies found significant positive impacts all both IYCF and growth (Guldan et al., 2000; Santos et al., 2001; Sherburne et al., 2018; Vazir et al., 2013; Waswa et al., 2015; Zaman et al., 2008; Zhang et al., 2013); while one study found significant positive impacts on growth but not on the IYCF practices. (Olney et al., 2015).

\section{Underweight}


Of the 11 studies that reported underweight, three $(27 \%)$ reported a statistically significant positive effect (Appendix Table A2). Among all included studies across all study designs: none of the RCTs measured and reported on underweight; 10 out of $51(20 \%)$ of the cluster randomised trials measured and reported on underweight and of these 10 studies, three (30\%) reported a statistically significant positive impact (Nair et al., 2017; Ruel et al., 2008; Saleem et al., 2014); while six (60\%) did not report any significant effect (I. M. Engebretsen et al., 2014; Gelli et al., 2018; Menon, Nguyen, Saha, Khaled, Sanghvi, et al., 2016; Olney et al., 2015; Saville et al., 2018; Waswa et al., 2015); and one study reported a significant negative impact (Fadnes et al., 2016). One out of the 16 (12\%) quasi-experimental studies measured and reported on underweight and it did not report any statistically significant positive impact (Schroeder et al., 2002).

\section{Publication bias and meta-regression}

The results of Egger's test were presented (Table 1). Publication bias was only observed in studies identified to estimate the effectiveness of interventions on EBF ( $p=0.012), M D D(p<0.001)$, and MMF $(p<0.001)$. However, the $p$ values for the Egger's test were 0.096 (for EIBF), 0.969 (for HAZ), 0.120 (for WHZ), and 0.194 (for WAZ), respectively, denoting absent of publication bias (Table 1). To examine the sources of heterogeneity, a stratified analysis was conducted for the core IYCF indicators and standard indicators of child growth in terms of number of participants and duration on intervention (Table 2). This study found that only EIBF was significantly associated with increased duration of intervention (OR = 1.31, 95\% Cl: $1.22-1.41 ; p<0.001)$ and increased number of participants $(\mathrm{OR}=1.12,95 \% \mathrm{Cl}: 1.03-1.29$; $\mathrm{p}<0.001)$ (Table 2).

$<$ Insert Table 1 \& Table 2 here>

\section{Discussion}

We documented evidence on the effectiveness of the NSBCC interventions on child growth. Our study showed a significant positive effect of NSBCC on the anthropometric outcomes (HAZ, WHZ and WAZ). These are encouraging and important findings for low and middle income countries in view of meeting the WHA and the SDG targets. We also found that slightly more studies had reported positive impact on HAZ and stunting in comparison to $\mathrm{WHZ}$ and wasting respectively. This reinforces that in addition to feeding, there are other acute factors such as childhood illnesses like diarrhea, unsafe water, poor sanitation and hygiene that are contributing to poor growth (Li, Kim, Vollmer, \& Subramanian, 2020) indicating that the NSBCC interventions need to incorporate multi-sectoral health and hygiene interventions. Other authors conducting meta-analysis on education interventions and child growth have reported varied findings. Panjwani and Heidkamp had found that interventions which provided nutrition education or counselling had small but significant impact on linear growth but not on ponderal growth (A. Panjwani \& R. Heidkamp, 2017). On the other hand, Lassi et al. had reported similar results to ours that complementary feeding education alone resulted in significant impact on both height and length growths (Z. S. Lassi, J. K. Das, G. Zahid, A. Imdad, \& Z.A. Bhutta, 2013b). Few specific studies included in 
our review reporting significant negative impacts on child growth need to be interpreted with caution in light of their short duration of less than six months (M. S. I. Engebretsen et al., 2014; Fadnes et al., 2016; Waswa et al., 2015) and of them, two had limited focus only on breastfeeding promotion (M. S. I. Engebretsen et al., 2014; Fadnes et al., 2016).

Our study results showed statistically significant positive effects of the NSBCC on EBF practices. Positive effects were also found on MDD and MMF but they were not statistically significant. Our findings are supported by the other existing literature which indicates that nutrition education or behavior change interventions significantly improve the IYCF practices (D. Arikpo et al., 2018; M. M. Graziose et al., 2018; S. Lamstein et al., 2014; T. Sanghvi et al., 2017; Shi \& Zhang, 2011). Our meta-analysis showed that there was overall no effect on EIBF. There could be other factors beyond knowledge and behavior that hinder EIBF, such as deep-rooted cultural issues or issues with health service providers, which are perhaps not adequately addressed by the NSBCC approaches (Ahishakiye, Bouwman, Brouwer, Vaandrager, \& Koelen, 2020; Rujumba et al., 2020). The non-significant impact observed for MDD and MMF could also be due to the NSBCC approaches being used to convey messages on the young children's diet are not adequate and easy for the target groups to understand in order to be impactful. Hence, this may point towards the need to adjust some of the NSBCC approaches and to use the more effective models.

We also aimed to understand the effectiveness of NSBCC tools or approaches. For EBF, interpersonal counselling (individual and/or group) alone or in combination with the use of media (IEC materials, mass media, phone messaging) and community mobilization activities were reported to be effective in most studies. On the other hand, it was less clear for EIBF as some studies documented positive impacts using interpersonal counselling (individual and/or group) with or without additional NSBCC elements while others did not find any impact with similar approaches. For MDD and MMF, the effective NSBCC tools ranged from interpersonal counselling (individual and/or group) only or in combination with other approaches like use of media (such as IEC materials, cooking demonstration promoting locally available foods, mass media) and community mobilization activities. For child growth, it did not emerge clearly which NSBCC tools were more effective. Whilst a few studies employing tools like interpersonal counselling (individual and/or group) with or without use of media (such as IEC materials, cooking demonstration, mass media) and community mobilization activities were found to have a significant positive impact; but most studies using similar approaches did not find such impact. Given the complex multi-sector, multi-dimensional and multi-impact pathways of nutrition, it is also difficult to tease out the impact of NSBCC alone on growth. Overall, interpersonal counselling is the most widely used and tested approach followed by its combination with large, medium or small media while community mobilization is the least integrated NSBCC approach.

One of our objectives was also to understand what NSBCC approaches or their combinations work best to improve IYCF and child nutrition. Through this study, we were unable to understand these associations as the NSBCC tools and approaches employed were heterogeneous, with varying intervention dosage and duration and dose frequency. Furthermore, the differences in findings between multi-country and multi- 
setting studies point that local factors might determine the outcomes, highlighting the importance of tailoring the NSBCC approaches, tools and content to the specific contexts and places.

\section{Recommendations}

Future studies need to align with the globally standardized and harmonized indicators recommended by the WHO on IYCF (WHO, 2008) and that of the WHA and the SDG targets on child growth (UNSCN, 2015; WHO, 2014) while reporting their outcomes. This will allow comparison and to measure the difference in outcomes.

Our findings had more than half of the included studies (56\%) conducted in rural setting. However, it is projected that almost $70 \%$ of the world's population will live in urban areas by 2050 (UN DESA, 2018). In view of the rapid urbanization and to embrace SDG principle of 'leaving no one behind,' future research settings need to increasingly encompass urban and peri-urban areas.

Future need for further robust research is also highlighted by other literatures (Dachi Arikpo et al., 2018; A.W Girard \& O. Olude, 2012; Matthew M. Graziose et al., 2018; Ellie Gresham, Julie E. Byles, Alessandra Bisquera, \& Alexis J. Hure, 2014; S. Lamstein et al., 2014; Lassi et al., 2013b; Shi \& Zhang, 2010) ). In this study, we recommend future studies to specify the exact types and combinations NSBCC interventions (e.g. interpersonal and/or group counselling with paper-based IEC materials; or interpersonal and/or group counselling with actual demonstrations; interpersonal and/or group counselling plus IEC materials and real demonstrations with usage of digital media, etc.) as well as their exact intervention dosage and duration, and dose frequency.

Future studies should also be conducted to reflect the varying contexts - different countries or geographic locations, urban and rural, food secure and food insecure. There is the necessity as well as the scope for innovations within all three categories of NSBCC approaches. Innovative methods need to be tested for interpersonal counselling while existing innovative media and community mobilization activities should be explored and studied for their effectiveness. Given the global galvanization of healthy diet movement and its environmental considerations by the recent EAT-Lancet commission report (Willett et al., 2019), the promotion of locally available foods through food and/or cooking demonstrations, in particular to promote healthy diet and optimal dietary diversity, ought to be separately and robustly evaluated as a potential and key NSBCC tools for widespread use. Specific tools or learning methodologies could also be adopted from other disciplines like education (e.g. effective learning methodologies) and psychology (e.g. emotional drivers of behavior change).

\section{Strengths And Limitations}

Our systematic review and meta-analysis has several strengths. It adopted a comprehensive search strategy including systematic search of appropriate databases, combing through the relevant reference lists and websites as well as reaching out to some of the concerned experts that resulted in a high 
number of papers identified for final inclusion. We were able to have a large pool of data as we looked through various data sources including grey literature, over a period a time. The review focused on different study designs - RCT, cluster randomised and quasi-experimental designs that provided a scope to distill the most rigorous evidence available. To our knowledge, this review is the first of its kind to look at four of the standard IYCF indicators as recommended by the WHO, including both breastfeeding and complementary feeding, as well as standard indicators of child growth. The review findings can be generalized to rural and urban settings as well as all countries across the developing context.

Some limitations of the review process need to be outlined. We only looked at four out of the eight core indicators recommended by the $\mathrm{WHO}$ and our meta-analysis was not conducted for stunting, underweight and wasting. The use of printed communication materials in the included studies may be underreported: if the studies only mentioned 'counselling,' or 'group learning', we assumed that it was the only approach used while printed materials usage was included only when they were clearly stated in the study. Furthermore, we were not able to analyse the findings by dose and/or frequency of the interventions due to the heterogeneous and combined nature of the NSBCC interventions and lack of information in some studies. In addition, the potential publication biases cannot be ruled out.

\section{Conclusions}

Improvement in IYCF practices and child nutritional status are imperative to attain the SDGs. Findings from our study show that the NSBCC interventions improve EBF and child anthropometric outcomes. The existing evidence thus indicate the importance of the NSBCC tools while planning all child nutrition programmes. More specific and rigorous research is required to further test the impact on child nutritional status with clearly specified and detailed NSBCC interventions.

\section{Declarations}

Conflict of Interest: None

Ethics approval: Not applicable

Consent to participate: Not applicable.

Consent for publication: Not applicable.

Availability of data and material: Data were within manuscript.

\section{References}

Aboud, F. E., \& Akhter, S. (2011). A cluster-randomized evaluation of a responsive stimulation and feeding intervention in bangladesh. Pediatrics, 127(5), e1191-1197. doi:10.1542/peds.2010-2160 
Aboud, F. E., Singla, D. R., Nahil, M. I., \& Borisova, I. (2013). Effectiveness of a parenting program in Bangladesh to address early childhood health, growth and development. Soc Sci Med, 97, 250-258. doi:10.1016/j.socscimed.2013.06.020

Ahishakiye, J., Bouwman, L., Brouwer, I. D., Vaandrager, L., \& Koelen, M. (2020). Prenatal infant feeding intentions and actual feeding practices during the first six months postpartum in rural Rwanda: a qualitative, longitudinal cohort study. International Breastfeeding Journal, 15(1), $29-29$. doi:10.1186/s13006-020-00275-y

Aidam, B. A., Perez-Escamilla, R., \& Lartey, A. (2005). Lactation counseling increases exclusive breastfeeding rates in Ghana. J Nutr, 135(7), 1691-1695. doi:10.1093/jn/135.7.1691

Ara, G., Khanam, M., Papri, N., Nahar, B., Haque, M. A., Kabir, I., \& Dibley, M. J. (2018). Peer counselling improves breastfeeding practices: A cluster randomized controlled trial in urban Bangladesh. Maternal \& Child Nutrition, 14(3), 1-1. doi:10.1111/mcn.12605

Arifeen, S. E., Hoque, D. M. E., Akter, T., Rahman, M., Hoque, M. E., Begum, K., . . Black, R. E. (2009). Effect of the Integrated Management of Childhood Illness strategy on childhood mortality and nutrition in a rural area in Bangladesh: a cluster randomised trial. The Lancet, 374(9687), 393-403.

doi:http://dx.doi.org/10.1016/S0140-6736(09)60828-X

Arikpo, D., Edet, E. S., Chibuzor, M. T., Odey, F., \& Caldwell, D. M. (2018). Educational interventions for improving primary caregiver complementary feeding practices for children aged 24 months and under. Cochrane library, 2018(5), CD011768. doi:10.1002/14651858.cd011768.pub2

Arikpo, D., Edet, E. S., Chibuzor, M. T., Odey, F., \& Caldwell, D. M. (2018). Educational interventions for improving primary caregiver complementary feeding practices for children aged 24 months and under. Cochrane Database Syst Rev, 5, Cd011768. doi:10.1002/14651858.CD011768.pub2

Aristiati Susiloretni, K., Sunarto, Krisnamurni, S., Yosef Didik Widiyanto, S., Yazid, A., \& Agus Wilopo, S. (2013). The Effectiveness of Multilevel Promotion of Exclusive Breastfeeding in Rural Indonesia. American Journal of Health Promotion, 28(2), e44-e55. doi:10.4278/ajhp.120425-QUAN-221

Begg, C. B., \& Mazumdar, M. (1994). Operating Characteristics of a Rank Correlation Test for Publication Bias. Biometrics, 50(4), 1088-1101. doi:10.2307/2533446

Bhandari, N., Bahl, R., Mazumdar, S., Martines, J., Black, R. E., \& Bhan, M. K. (2003). Effect of communitybased promotion of exclusive breastfeeding on diarrhoeal illness and growth: a cluster randomised controlled trial. Lancet, 361(9367), 1418-1423. doi:10.1016/s0140-6736(03)13134-0

Bhandari, N., Bahl, R., Nayyar, B., Khokhar, P., Rohde, J. E., \& Bhan, M. K. (2001). Food supplementation with encouragement to feed it to infants from 4 to 12 months of age has a small impact on weight gain. J Nutr, 131(7), 1946-1951. doi:10.1093/jn/131.7.1946 
Bhandari, N., Mazumder, S., Bahl, R., Martines, J., Black, R. E., \& Bhan, M. K. (2004). An educational intervention to promote appropriate complementary feeding practices and physical growth in infants and young children in Rural Haryana, India. Journal of Nutrition, 134(9), 2342-2348.

Bhutta, Z. A., Das, J. K., Rizvi, A., Gaffey, M. F., Walker, N., Horton, S., . . Black, R. E. (2013). Evidencebased interventions for improvement of maternal and child nutrition: what can be done and at what cost? Lancet, 382(9890), 452-477. doi:10.1016/s0140-6736(13)60996-4

Bortolini, G. A., \& Vitolo, M. R. (2012). The impact of systematic dietary counseling during the first year of life on prevalence rates of anemia and iron deficiency at 12-16 months. J Pediatr (Rio J), 88(1), 33-39. doi:10.2223/jped.2156

Brasington, A., Abdelmegeid, A., Dwivedi, V., Kols, A., Kim, Y. M., Khadka, N., ... Gibson, A. (2016). Promoting Healthy Behaviors among Egyptian Mothers: A Quasi-Experimental Study of a Health Communication Package Delivered by Community Organizations. PLOS ONE, 11(3), e0151783. doi:10.1371/journal.pone.0151783

Brown, L. V., Zeitlin, M. F., Peterson, K. E., Chowdhury, A. M., Rogers, B. L., Weld, L. H., \& Gershoff, S. N. (1992). Evaluation of the impact of weaning food messages on infant feeding practices and child growth in rural Bangladesh. Am J Clin Nutr, 56(6), 994-1003. doi:10.1093/ajcn/56.6.994

Byrd, K., Dentz, H. N., Williams, A., Kiprotich, M., Pickering, A. J., Omondi, R., . . Stewart, C. P. (2018). A behaviour change intervention with lipid-based nutrient supplements had little impact on young child feeding indicators in rural Kenya. Maternal and Child Nutrition. doi:http://dx.doi.org/10.1111/mcn.12660

Campbell, R. K., Hurley, K. M., Shamim, A. A., Shaikh, S., Chowdhury, Z. T., Mehra, S., . . Christian, P. (2016). Effect of complementary food supplementation on breastfeeding and home diet in rural Bangladeshi children. American Journal of Clinical Nutrition, 104(5), 1450-1458. doi:10.3945/ajcn.116.135509

Caulfield, L. E., Huffman, S. L., \& Piwoz, E. G. (1999). Interventions to Improve Intake of Complementary Foods by Infants 6 to 12 Months of Age in Developing Countries: Impact on Growth and on the Prevalence of Malnutrition and Potential Contribution to Child Survival. Food and Nutrition Bulletin, 20(2), 183-200. doi:10.1177/156482659902000203

Development Initiatives. (2018). 2018 Global Nutrition Report: Shining a light to spur action on nutrition. Retrieved from Bristol, UK:

Dewey, K. G., \& Adu-Afarwuah, S. (2008). Systematic review of the efficacy and effectiveness of complementary feeding interventions in developing countries. Matern Child Nutr, 4 Suppl 1, 24-85. doi:10.1111/j.1740-8709.2007.00124.x 
Dewey, K. G., \& Adu-Afarwuah, S. (2008). Systematic review of the efficacy and effectiveness of complementary feeding interventions in developing countries. Maternal and child nutrition, 4(s1), 24-85. doi:10.1111/j.1740-8709.2007.00124.x

Dougherty, L., Stammer, E., Derbile, E., Dery, M., Yahaya, W., Gle, D. B., . . Fotso, J. C. (2018). A MixedMethods Evaluation of a Community-Based Behavior Change Program to Improve Maternal Health Outcomes in the Upper West Region of Ghana. J Health Commun, 23(1), 80-90. doi:10.1080/10810730.2017.1414901

Egger, M., Davey Smith, G., Schneider, M., \& Minder, C. (1997). Bias in meta-analysis detected by a simple, graphical test. BMJ. British medical journal (Clinical research ed.), 315(7109), 629-634.

Engebretsen, I. M., Jackson, D., Fadnes, L. T., Nankabirwa, V., Diallo, A. H., Doherty, T., . . Tylleskar, T. (2014). Growth effects of exclusive breastfeeding promotion by peer counsellors in sub-Saharan Africa: the cluster-randomised PROMISE EBF trial. BMC Public Health, 14, 633. doi:http://dx.doi.org/10.1186/1471-2458-14-633

Engebretsen, M. S. I., Nankabirwa, V., Doherty, T., Diallo, A. H., Nankunda, J., Fadnes, L. T., . . Tumwine, J. K. (2014). Early infant feeding practices in three African countries: the PROMISE-EBF trial promoting exclusive breastfeeding by peer counsellors. International Breastfeeding Journal, 9. doi:http://dx.doi.org/10.1186/1746-4358-9-19

Fadnes, L. T., Nankabirwa, V., Engebretsen, I. M., Sommerfelt, H., Birungi, N., Lombard, C., . . Tumwine, J. K. (2016). Effects of an exclusive breastfeeding intervention for six months on growth patterns of 4-5 year old children in Uganda: the cluster-randomised PROMISE EBF trial. BMC Public Health, 16(1), 1-9. doi:10.1186/s12889-016-3234-3

Flax, V. L., Negerie, M., Ibrahim, A. U., Leatherman, S., Daza, E. J., \& Bentley, M. E. (2014). Integrating group counseling, cell phone messaging, and participant-generated songs and dramas into a microcredit program increases Nigerian women's adherence to international breastfeeding recommendations. $J$ Nutr, 144(7), 1120-1124. doi:10.3945/jn.113.190124

Gabida, M., Chemhuru, M., Tshimanga, M., Gombe, N. T., Takundwa, L., \& Bangure, D. (2015). Effect of distribution of educational material to mothers on duration and severity of diarrhoea and pneumonia, Midlands Province, Zimbabwe: a cluster randomized controlled trial. International Breastfeeding Journal, 10(1), 1-12. doi:10.1186/s13006-015-0037-6

Gelli, A., Margolies, A., Santacroce, M., Roschnik, N., Twalibu, A., Katundu, M., . . Ruel, M. (2018). Using a Community-Based Early Childhood Development Center as a Platform to Promote Production and Consumption Diversity Increases Children's Dietary Intake and Reduces Stunting in Malawi: A ClusterRandomized Trial. Journal of Nutrition, 148(10), 1587-1597. doi:http://dx.doi.org/10.1093/jn/nxy148 
Girard, A. W., \& Olude, O. (2012). Nutrition education and counselling provided during pregnancy: effects on maternal, neonatal and child health outcomes. Paediatr Perinat Epidemiol, 26 Suppl 1, 191-204. doi:10.1111/j.1365-3016.2012.01278.x

Girard, A. W., \& Olude, O. (2012). Nutrition Education and Counselling Provided during Pregnancy: Effects on Maternal, Neonatal and Child Health Outcomes: Nutrition education and counseling during pregnancy. Paediatric and perinatal epidemiology, 26, 191-204. doi:10.1111/j.1365-3016.2012.01278.x

Graziose, M. M., Downs, S. M., O'Brien, Q., \& Fanzo, J. (2018). Systematic review of the design, implementation and effectiveness of mass media and nutrition education interventions for infant and young child feeding. Public Health Nutr, 21(2), 273-287. doi:10.1017/s1368980017002786

Graziose, M. M., Downs, S. M., O’Brien, Q., \& Fanzo, J. (2018). Systematic review of the design, implementation and effectiveness of mass media and nutrition education interventions for infant and young child feeding. Public health nutrition, 21(2), 273-287. doi:10.1017/S1368980017002786

Greenland, K., Chipungu, J., Curtis, V., Schmidt, W. P., Siwale, Z., Mudenda, M., . . Chilengi, R. (2016). Multiple behaviour change intervention for diarrhoea control in Lusaka, Zambia: a cluster randomised trial. The Lancet Global Health, 4(12), e966-e977. doi:http://dx.doi.org/10.1016/S2214$109 \times \% 2816 \% 2930262-5$

Gresham, E., Byles, J. E., Bisquera, A., \& Hure, A. J. (2014). Effects of dietary interventions on neonatal and infant outcomes: a systematic review and meta-analysis. The American journal of clinical nutrition, 100(5), 1298-1321. doi:10.3945/ajcn.113.080655

Gresham, E., Byles, J. E., Bisquera, A., \& Hure, A. J. (2014). Effects of dietary interventions on neonatal and infant outcomes: a systematic review and meta-analysis. Am J Clin Nutr, 100(5), 1298-1321. doi:10.3945/ajcn.113.080655

Guldan, G. S., Fan, H. C., Ma, X., Ni, Z. Z., Xiang, X., \& Tang, M. Z. (2000). Culturally appropriate nutrition education improves infant feeding and growth in rural Sichuan, China. J Nutr, 130(5), 1204-1211. doi:10.1093/jn/130.5.1204

Haider, R., Ashworth, A., Kabir, I., \& Huttly, S. R. (2000). Effect of community-based peer counsellors on exclusive breastfeeding practices in Dhaka, Bangladesh: a randomised controlled trial [see commments]. Lancet, 356(9242), 1643-1647.

Higgins, J. P. T., \& Thompson, S. G. (2002). Quantifying heterogeneity in a meta-analysis. Statistics in medicine, 21(11), 1539-1558. doi:10.1002/sim.1186

Higgins, J. P. T., \& Thompson, S. G. (2004). Controlling the risk of spurious findings from meta-regression. Statistics in medicine, 23(11), 1663-1682. doi:10.1002/sim.1752 
Imdad, A., Yakoob, M. Y., \& Bhutta, Z. A. (2011). Impact of maternal education about complementary feeding and provision of complementary foods on child growth in developing countries. BMC Public Health, 11 Supp/ 3, S25. doi:10.1186/1471-2458-11-s3-s25

Jakobsen, M. S., Sodemann, M., Biai, S., Nielsen, J., \& Aaby, P. (2008). Promotion of exclusive breastfeeding is not likely to be cost effective in West Africa. A randomized intervention study from Guinea-Bissau. Acta Paediatr, 97(1), 68-75. doi:10.1111/j.1651-2227.2007.00532.x

Jannat, K., Stephen, L. P., Unicomb, L., Rahman, M., Winch, P. J., Sarker, P. M., . . Stewart, C. P. (2018). Complementary feeding practices among rural Bangladeshi mothers: Results from WASH Benefits study. Maternal and Child Nutrition. doi:http://dx.doi.org/10.1111/mcn.12654

Kang, Y., Suh, Y. K., Debele, L., Juon, H.-S., \& Christian, P. (2017). Effects of a community-based nutrition promotion programme on child feeding and hygiene practices among caregivers in rural Eastern Ethiopia. Public Health Nutrition, 20(8), 1461-1472. doi:http://dx.doi.org/10.1017/S1368980016003347

Kilaru, A., Griffiths, P. L., Ganapathy, S., \& Ghosh, S. (2005). Community-based nutrition education for improving infant growth in rural Karnataka. Indian Pediatr, 42(5), 425-432.

Kim, S. S., Nguyen, P. H., Tran, L. M., Sanghvi, T., Mahmud, Z., Haque, M. R., . . Menon, P. (2018). LargeScale Social and Behavior Change Communication Interventions Have Sustained Impacts on Infant and Young Child Feeding Knowledge and Practices: Results of a 2-Year Follow-Up Study in Bangladesh. Journal of Nutrition, 148(10), 1605-1614. doi:http://dx.doi.org/10.1093/jn/nxy147

Kim, S. S., Rawat, R., Mwangi, E. M., Tesfaye, R., Abebe, Y., Baker, J., . . Menon, P. (2016). Exposure to Large-Scale Social and Behavior Change Communication Interventions Is Associated with Improvements in Infant and Young Child Feeding Practices in Ethiopia. PLOS ONE, 11(10), e0164800. doi:10.1371/journal.pone.0164800

Kimani-Murage, E. W., Norris, S. A., Mutua, M. K., Wekesah, F., Wanjohi, M., Muhia, N., . . Griffiths, P. L. (2016). Potential effectiveness of Community Health Strategy to promote exclusive breastfeeding in urban poor settings in Nairobi, Kenya: a quasi-experimental study. Journal of developmental origins of health and disease, 7(2), 172-184. doi:http://dx.doi.org/10.1017/S2040174415007941

Knapp, G., \& Hartung, J. (2003). Improved tests for a random effects meta-regression with a single covariate. Statistics in medicine, 22(17), 2693-2710. doi:10.1002/sim.1482

Kuchenbecker, J., Reinbott, A., Mtimuni, B., Krawinkel, M. B., \& Jordan, I. (2017). Nutrition education improves dietary diversity of children 6-23 months at community-level: Results from a cluster randomized controlled trial in Malawi. PLOS ONE, 12(4). doi:http://dx.doi.org/10.1371/journal.pone. 0175216

Kushwaha, K. P., Sankar, J., Sankar, M. J., Gupta, A., Dadhich, J. P., Gupta, Y. P., . . Sharma, B. (2014). Effect of peer counselling by mother support groups on infant and young child feeding practices: the 
Lalitpur experience. PLoS ONE, 9(11), e109181. doi:10.1371/journal.pone.0109181

Lamstein, S., Perez-Escamilla, R., Koniz-Booher, P., Begin, F., Adeyemi, S., Kaligirwa, C., . . Adebisi, B. (2018). The Community Infant and Young Child Feeding Counselling Package in Kaduna State, Nigeria: A Mixed Methods Evaluation. Final Report. Arlington, VA: Strengthening Partnerships, Results, and Innovations in Nutrition Globally (SPRING) project.

Lamstein, S., Stillman, T., Koniz-Booher, P., Aakesson, A., Collaiezzi, B., Williams, T., . . Anson, M. (2014). Evidence of Effective Approaches to Social and Behavior Change Communication for Preventing and Reducing Stunting and Anemia: Findings from a Systematic Literature Review. Retrieved from

Lamstein, S., T. Stillman, P. Koniz-Booher, A. Aakesson, B. Collaiezzi, T. Williams, K. B., \& , \& M. Anson. (2014). Evidence of Effective Approaches to Social and Behavior Change Communication for Preventing and Reducing Stunting and Anemia: Report from a Systematic Literature Review. Retrieved from Arlington, VA:

Lassi, Z. S., Das, J. K., Zahid, G., Imdad, A., \& Bhutta, Z. A. (2013a). Impact of education and provision of complementary feeding on growth and morbidity in children less than 2 years of age in developing countries: a systematic review. BMC Public Health, 13 Supp/ 3, S13. doi:10.1186/1471-2458-13-s3-s13

Lassi, Z. S., Das, J. K., Zahid, G., Imdad, A., \& Bhutta, Z. A. (2013b). Impact of education and provision of complementary feeding on growth and morbidity in children less than 2 years of age in developing countries: a systematic review. BMC public health, 13(Suppl 3), S13. doi:10.1186/1471-2458-13-s3-s13

le Roux, I. M., le Roux, K., Mbeutu, K., Comulada, W. S., Desmond, K. A., \& Rotheram-Borus, M. J. (2011). A randomized controlled trial of home visits by neighborhood mentor mothers to improve children's nutrition in South Africa. Vulnerable Child Youth Stud, 6(2), 91-102. doi:10.1080/17450128.2011.564224

Le Roux, I. M., Rotheram-Borus, M. J., Stein, J., \& Tomlinson, M. (2014). The impact of paraprofessional home visitors on infants' growth and health at 18 months. Vulnerable Children \& Youth Studies, 9(4), 291304. doi:10.1080/17450128.2014.940413

Leite, A. J., Puccini, R. F., Atalah, A. N., Alves Da Cunha, A. L., \& Machado, M. T. (2005). Effectiveness of home-based peer counselling to promote breastfeeding in the northeast of Brazil: a randomized clinical trial. Acta Paediatr, 94(6), 741-746. doi:10.1111/j.1651-2227.2005.tb01974.x

Lewycka, S., Mwansambo, C., Rosato, M., Kazembe, P., Phiri, T., Mganga, A., . . Costello, A. (2013). Effect of women's groups and volunteer peer counselling on rates of mortality, morbidity, and health behaviours in mothers and children in rural Malawi (MaiMwana): A factorial, cluster-randomised controlled trial. The Lancet, 381(9879), 1721-1735. doi:http://dx.doi.org/10.1016/S0140-6736\%2812\%2961959-X

Li, Z., Kim, R., Vollmer, S., \& Subramanian, S. V. (2020). Factors Associated With Child Stunting, Wasting, and Underweight in 35 Low- and Middle-Income Countries. JAMA network open, 3(4), e203386. 
Marquis, G. S., Colecraft, E. K., Kanlisi, R., Aidam, B. A., Atuobi-Yeboah, A., Pinto, C., \& Aryeetey, R. (2018). An agriculture-nutrition intervention improved children's diet and growth in a randomized trial in Ghana. Maternal \& Child Nutrition, 14, N.PAG-N.PAG. doi:10.1111/mcn.12677

Martins, V. J. B., Toledo Florêncio, T. M. M., Grillo, L. P., do Carmo P Franco, M., Martins, P. A., Clemente, A. P. G., . . Sawaya, A. L. (2011). Long-lasting effects of undernutrition. International Journal of Environmental Research and Public Health, 8(6), 1817-1846. doi:10.3390/ijerph8061817

Menon, P., Nguyen, P. H., Saha, K. K., Khaled, A., Kennedy, A., Tran, L. M., . . Rawat, R. (2016). Impacts on Breastfeeding Practices of At-Scale Strategies That Combine Intensive Interpersonal Counseling, Mass Media, and Community Mobilization: Results of Cluster-Randomized Program Evaluations in Bangladesh and Viet Nam. PLoS Med, 13(10), e1002159. doi:10.1371/journal.pmed.1002159

Menon, P., Nguyen, P. H., Saha, K. K., Khaled, A., Sanghvi, T., Baker, J., . . Rawat, R. (2016). Combining intensive counseling by frontline workers with a nationwide mass media campaign has large differential impacts on complementary feeding practices but not on child growth: Results of a cluster-randomized program evaluation in Bangladesh1-3. Journal of Nutrition, 146(10), 2075-2084.

doi:http://dx.doi.org/10.3945/JN.116.232314

Moher, D., Liberati, A., Tetzlaff, J., \& Altman, D. G. (2009). Preferred reporting items for systematic reviews and meta-analyses: the PRISMA statement. PLoS Med, 6(7), e1000097. doi:10.1371/journal.pmed.1000097

More, N. S., Das, S., Bapat, U., Alcock, G., Manjrekar, S., Kamble, V., .. Osrin, D. (2017). Community resource centres to improve the health of women and children in informal settlements in Mumbai: a cluster-randomised, controlled trial. The Lancet Global Health, 5(3), e335-e349.

doi:http://dx.doi.org/10.1016/S2214-109X\%2816\%2930363-1

Muhoozi, G. K. M., Atukunda, P., Diep, L. M., Mwadime, R., Kaaya, A. N., Skaare, A. B., . . Iversen, P. O. (2018). Nutrition, hygiene, and stimulation education to improve growth, cognitive, language, and motor development among infants in Uganda: A cluster-randomized trial. Maternal and Child Nutrition, 14(2), e12527. doi:http://dx.doi.org/10.1111/mcn.12527

Mukuria, A. G., Martin, S. L., Egondi, T., Bingham, A., \& Thuita, F. M. (2016). Role of Social Support in Improving Infant Feeding Practices in Western Kenya: A Quasi-Experimental Study. Global health, science and practice, 4(1), 55-72. doi:http://dx.doi.org/10.9745/GHSP-D-15-00197

Nair, N., Tripathy, P., Sachdev, H. S., Pradhan, H., Bhattacharyya, S., Gope, R., . . Prost, A. (2017). Effect of participatory women's groups and counselling through home visits on children's linear growth in rural eastern India (CARING trial): a cluster-randomised controlled trial. The Lancet Global Health, 5(10), e1004e1016. doi:http://dx.doi.org/10.1016/S2214-109X\%2817\%2930339-X 
Negash, C., Belachew, T., Henry, C. J., Kebebu, A., Abegaz, K., \& Whiting, S. J. (2014). Nutrition education and introduction of broad bean-based complementary food improves knowledge and dietary practices of caregivers and nutritional status of their young children in Hula, Ethiopia. Food Nutr Bull, 35(4), 480-486. doi:10.1177/156482651403500409

Nguyen, P. H., Kim, S. S., Sanghvi, T., Mahmud, Z., Tran, L. M., Shabnam, S., . . Menon, P. (2017). Integrating Nutrition Interventions into an Existing Maternal, Neonatal, and Child Health Program Increased Maternal Dietary Diversity, Micronutrient Intake, and Exclusive Breastfeeding Practices in Bangladesh: Results of a Cluster-Randomized Program Evaluation. The Journal of Nutrition, 147(12), 2326.

Nikièma, L., Huybregts, L., Martin-Prevel, Y., Donnen, P., Lanou, H., Grosemans, J., . . Kolsteren, P. (2017). Effectiveness of facility-based personalized maternal nutrition counseling in improving child growth and morbidity up to 18 months: A cluster-randomized controlled trial in rural Burkina Faso. PLOS ONE, 12(5). doi:http://dx.doi.org/10.1371/journal.pone.0177839

Olney, D. K., Pedehombga, A., Ruel, M. T., \& Dillon, A. (2015). A 2-Year Integrated Agriculture and Nutrition and Health Behavior Change Communication Program Targeted to Women in Burkina Faso Reduces Anemia, Wasting, and Diarrhea in Children 3-12.9 Months of Age at Baseline: A Cluster-Randomized Controlled Trial 1-3. The Journal of Nutrition, 145(6), 1317-1324A.

Pachon, H., Schroeder, D. G., Marsh, D. R., Dearden, K. A., Ha, T. T., \& Lang, T. T. (2002). Effect of an integrated child nutrition intervention on the complementary food intake of young children in rural north Viet Nam. Food Nutr Bull, 23(4 Suppl), 62-69.

Panjwani, A., \& Heidkamp, R. (2017). Complementary Feeding Interventions Have a Small but Significant Impact on Linear and Ponderal Growth of Children in Low- and Middle-Income Countries: A Systematic Review and Meta-Analysis. J Nutr, 147(11), 2169s-2178s. doi:10.3945/jn.116.243857

Panjwani, A., \& Heidkamp, R. (2017). Complementary Feeding Interventions Have a Small but Significant Impact on Linear and Ponderal Growth of Children in Low- and Middle-Income Countries: A Systematic Review and Meta-Analysis. The Journal of nutrition, 147(11), jn243857. doi:10.3945/jn.116.243857

Penfold, S., Manzi, F., Mkumbo, E., Temu, S., Jaribu, J., Shamba, D. D., .. Armstrong Schellenberg, J. (2014). Effect of home-based counselling on newborn care practices in southern tanzania one year after implementation: A cluster-randomised controlled trial. BMC Pediatrics, 14(1), 187. doi:http://dx.doi.org/10.1186/1471-2431-14-187

Penny, M. E., Creed-Kanashiro, H. M., Robert, R. C., Narro, M. R., \& et al. (2005). Effectiveness of an educational intervention delivered through the health services to improve nutrition in young children: a cluster-randomised controlled trial. The Lancet, 365(9474), 1863-1872.

doi:http://dx.doi.org/10.1016/S0140-6736(05)66426-4 
Rawat, R., Phuong Hong, N., Lan Mai, T., Hajeebhoy, N., Huan Van, N., Baker, J., ... Nguyen, H. V. (2017). Social Franchising and a Nationwide Mass Media Campaign Increased the Prevalence of Adequate Complementary Feeding in Vietnam: A Cluster-Randomized Program Evaluation. Journal of Nutrition, 147(4), 670-679. doi:10.3945/jn.116.243907

Rockers, P. C., Zanolini, A., Bowen, B., Mwaba Moono, C., Hughes, R. C., Hamer, D. H., \& Fink, G. (2018). Two-year impact of community-based health screening and parenting groups on child development in Zambia: Follow-up to a cluster-randomized controlled trial. PLoS Medicine, 15(4).

doi:http://dx.doi.org/10.1371/journal.pmed.1002555

Roy, S. K., Fuchs, G. J., Mahmud, Z., Ara, G., Islam, S., Shafique, S., . . Chakraborty, B. (2005). Intensive nutrition education with or without supplementary feeding improves the nutritional status of moderatelymalnourished children in Bangladesh. J Health Popul Nutr, 23(4), 320-330.

Roy, S. K., Jolly, S. P., Shafique, S., Fuchs, G. J., Mahmud, Z., Chakraborty, B., \& Roy, S. (2007). Prevention of malnutrition among young children in rural Bangladesh by a food-health-care educational intervention: a randomized, controlled trial. Food Nutr Bull, 28(4), 375-383. doi:10.1177/156482650702800401

Ruel, M. T., \& Alderman, H. (2013). Nutrition-sensitive interventions and programmes: how can they help to accelerate progress in improving maternal and child nutrition? Lancet, 382(9891), 536-551. doi:10.1016/s0140-6736(13)60843-0

Ruel, M. T., Menon, P., Habicht, J.-P., Loechl, C., Bergeron, G., Pelto, G., .. Hankebo, B. (2008). Age-based preventive targeting of food assistance and behaviour change and communication for reduction of childhood undernutrition in Haiti: a cluster randomised trial. The Lancet, 371(9612), 588-595. doi:http://dx.doi.org/10.1016/S0140-6736(08)60271-8

Rujumba, J., Ndeezi, G., Nankabirwa, V., Kwagala, M., Mukochi, M., Diallo, A. H., . . Tumwine, J. (2020). "If I have money, I cannot allow my baby to breastfeed only ..." barriers and facilitators to scale-up of peer counselling for exclusive breastfeeding in Uganda. International Breastfeeding Journal, 15(1), 43. doi:10.1186/s13006-020-00287-8

Saggurti, N., x Yamini, A., Porwal, A., Schooley, J., Das, R., Kande, N., . . Hay, K. (2018). Effect of health intervention integration within women's self-help groups on collectivization and healthy practices around reproductive, maternal, neonatal and child health in rural India. PLOS ONE, 13(8).

doi:http://dx.doi.org/10.1371/journal.pone.0202562

Saleem, A. F., Mahmud, S., Baig-Ansari, N., \& Zaidi, A. K. (2014). Impact of maternal education about complementary feeding on their infants' nutritional outcomes in low- and middle-income households: a community-based randomized interventional study in Karachi, Pakistan. Journal of health, population, and nutrition, 32(4), 623-633. 
Sanghvi, T., Seidel, R., Baker, J., \& Jimerson, A. (2017). Using behavior change approaches to improve complementary feeding practices. Matern Child Nutr, 13 Suppl 2. doi:10.1111/mcn.12406

Sanghvi, T., Seidel, R., Baker, J., \& Jimerson, A. (2017). Using behavior change approaches to improve complementary feeding practices. Maternal \& Child Nutrition, 13(S2), n/a. doi:10.1111/mcn.12406

Santos, I., Victora, C. G., Martines, J., Goncalves, H., Gigante, D. P., Valle, N. J., \& Pelto, G. (2001). Nutrition counseling increases weight gain among Brazilian children. J Nutr, 131(11), 2866-2873.

doi:10.1093/jn/131.11.2866

Saville, N. M., Shrestha, B. P., Style, S., Harris-Fry, H., Beard, B. J., Sen, A., . . Costello, A. (2018). Impact on birth weight and child growth of Participatory Learning and Action women's groups with and without transfers of food or cash during pregnancy: Findings of the low birth weight South Asia clusterrandomised controlled trial (LBWSAT) in Nepal. PLOS ONE, 13(5).

doi:http://dx.doi.org/10.1371/journal.pone.0194064

Schroeder, D. G., Pachon, H., Dearden, K. A., Kwon, C. B., Ha, T. T., Lang, T. T., \& Marsh, D. R. (2002). An integrated child nutrition intervention improved growth of younger, more malnourished children in northern Viet Nam. Food Nutr Bull, 23(4 Suppl), 53-61.

Seetha, A., Tsusaka, T. W., Munthali, T. W., Musukwa, M., Mwangwela, A., Kalumikiza, Z., . . Okori, P. (2018). How immediate and significant is the outcome of training on diversified diets, hygiene and food safety? An effort to mitigate child undernutrition in rural Malawi. Public Health Nutrition, 21(6), 11561166. doi:10.1017/S1368980017003652

Sharp S. (1998). sbe23: meta-analysis regression. Stata Technical Bulletin, 42, 16-22.

Sherburne, L., Math, S., Griffiths, M., Sacci, I., \& O’Donnell, C. (2018). “Grow Together” Campaign in Cambodia: A Game-changer for Children's Healthy Growth.

Shi, L., \& Zhang, J. (2010). Recent Evidence of the Effectiveness of Educational Interventions for Improving Complementary Feeding Practices in Developing Countries. Journal of tropical pediatrics (1980), 57(2), 91-98. doi:10.1093/tropej/fmq053

Shi, L., \& Zhang, J. (2011). Recent evidence of the effectiveness of educational interventions for improving complementary feeding practices in developing countries. J Trop Pediatr, 57(2), 91-98. doi:10.1093/tropej/fmq053

Shi, L., Zhang, J., Wang, Y., Caulfield, L. E., \& Guyer, B. (2010). Effectiveness of an educational intervention on complementary feeding practices and growth in rural China: a cluster randomised controlled trial. Public Health Nutr, 13(4), 556-565. doi:10.1017/s1368980009991364

Singh, A., Klemm, R. D. W., Mundy, G., Pandey Rana, P., Pun, B., \& Cunningham, K. (2018). Improving maternal, infant and young child nutrition in Nepal via peer mobilization. Public Health Nutr, 21(4), 796- 
Singla, D. R., Kumbakumba, E., \& Aboud, F. E. (2015). Effects of a parenting intervention to address maternal psychological wellbeing and child development and growth in rural Uganda: a communitybased, cluster randomised trial. Lancet Glob Health, 3(8), e458-e469. doi:10.1016/s2214-109x(15)000996

SPRING. (2019). Moving Nutrition Social and Behavior Change Forward. Retrieved from https://www.spring-nutrition.org/publications/briefs/moving-nutrition-social-and-behavior-changeforward

Tahir, N. M., \& Al-Sadat, N. (2013). Does telephone lactation counselling improve breastfeeding practices?: A randomised controlled trial. International Journal of Nursing Studies, 50(1), 16-25. doi:10.1016/j.ijnurstu.2012.09.006

The Cochrane Public Health Group. (2011). Guide for developing a public health protocol. .

Tomlinson, M., Doherty, T., ljumba, P., Jackson, D., Lawn, J., Persson, L. Å., . . Chopra, M. (2014). Goodstart: a cluster randomised effectiveness trial of an integrated, community-based package for maternal and newborn care, with prevention of mother-to-child transmission of HIV in a South African township. Tropical Medicine \& International Health, 19(3), 256-266. doi:10.1111/tmi.12257

Tylleskar, T., Jackson, D., Meda, N., Engebretsen, I. M. S., Chopra, M., Diallo, A. H., . . Tumwine, J. K. (2011). Exclusive breastfeeding promotion by peer counsellors in sub-Saharan Africa (PROMISE-EBF): A cluster-randomised trial. The Lancet, 378(9789), 420-427. doi:http://dx.doi.org/10.1016/S01406736\%2811\%2960738-1

UN. (2015). The Millenium Development Goals Report. Retrieved from

UN DESA. (2018). World Urbanisation Prospects 2018.

Unger, J. A., Ronen, K., Perrier, T., DeRenzi, B., Slyker, J., Drake, A. L., . . J John-Stewart, G. (2018). Short message service communication improves exclusive breastfeeding and early postpartum contraception in a low- to middle-income country setting: a randomised trial. BJOG: An International Journal of Obstetrics \& Gynaecology, 125(12), 1620-1629. doi:10.1111/1471-0528.15337

UNICEF. (2013). Improving Child Nutrition: The Achievable Imperative for Global Progress. Retrieved from New York: UNICEF:

UNSCN. (2015). Nutrition Targets and Indicators for the Post-2015 Sustainable Development Goals: Accountability for the Measurement of Results in Nutrition, A Technical Note.

Vazir, S., Engle, P., Balakrishna, N., Griffiths, P. L., Johnson, S. L., Creed-Kanashiro, H., . . Bentley, M. E. (2013). Cluster-randomized trial on complementary and responsive feeding education to caregivers found 
improved dietary intake, growth and development among rural Indian toddlers. Matern Child Nutr, 9(1), 99117. doi:10.1111/j.1740-8709.2012.00413.x

Victora, C. G., Adair, L., Fall, C., Hallal, P. C., Martorell, R., Richter, L., . . Sachdev, H. S. (2008). Maternal and child undernutrition: consequences for adult health and human capital. Lancet, 371 North American Edition(9609), 340-357. doi:10.1016/S0140-6736(07)61692-4

Vitolo, M. R., Bortolini, G. A., Feldens, C. A., \& Drachler Mde, L. (2005). [Impacts of the 10 Steps to Healthy Feeding in Infants: a randomized field trial]. Cad Saude Publica, 21(5), 1448-1457. doi:/S0102$311 \times 2005000500018$

Waiswa, P., Pariyo, G., Kallander, K., Akuze, J., Namazzi, G., Ekirapa-Kiracho, E., . . Peterson, S. (2015). Effect of the Uganda Newborn Study on care-seeking and care practices: a cluster-randomised controlled trial. Glob Health Action, 8, 24584. doi:10.3402/gha.v8.24584

Waswa, L. M., Jordan, I., Herrmann, J., Krawinkel, M. B., \& Keding, G. B. (2015). Community-based educational intervention improved the diversity of complementary diets in western Kenya: results from a randomized controlled trial. Public Health Nutr, 18(18), 3406-3419. doi:10.1017/s1368980015000920

White, S., Schmidt, W., Sahanggamu, D., Fatmaningrum, D., van Liere, M., \& Curtis, V. (2016). Can gossip change nutrition behaviour? Results of a mass media and community-based intervention trial in East Java, Indonesia. Tropical Medicine and International Health, 21(3), 348-364.

doi:http://dx.doi.org/10.1111/tmi.12660

WHO. (2008). Indicators for assessing infant and young child feeding practices: Part 1: Definitions.

WHO. (2014). Global nutrition targets 2025: policy brief series (WHO/NMH/NHD/14.2). . Geneva: World Health Organization.

Willett, W., Rockstrom, J., Loken, B., Springmann, M., Lang, T., Vermeulen, S., . . Murray, C. J. L. (2019). Food in the Anthropocene: the EAT-Lancet Commission on healthy diets from sustainable food systems. Lancet, 393(10170), 447-492. doi:10.1016/s0140-6736(18)31788-4

World Bank. (2018). World Bank list of economies (June 2018).

Younes, L., Houweling, T. A., Azad, K., Kuddus, A., Shaha, S., Haq, B., . . Fottrell, E. (2015). The effect of participatory women's groups on infant feeding and child health knowledge, behaviour and outcomes in rural Bangladesh: a controlled before-and-after study. Journal of Epidemiology and Community Health, 69(4), 374-381. doi:http://dx.doi.org/10.1136/jech-2014-204271

Zaman, S., Ashraf, R. N., \& Martines, J. (2008). Training in Complementary Feeding Counselling of Healthcare Workers and Its Influence on Maternal Behaviours and Child Growth: A Cluster-randomized Controlled Trial in Lahore, Pakistan. Journal of Health, Population and Nutrition, 26(2), 210-222. 
Zhang, J., Shi, L., Chen, D. F., Wang, J., \& Wang, Y. (2013). Effectiveness of an educational intervention to improve child feeding practices and growth in rural China: Updated results at 18 months of age. Maternal and Child Nutrition, 9(1), 118-129. doi:http://dx.doi.org/10.1111/j.1740-8709.2012.00447.x

\section{Tables}

Table 1. Assessing publication bias

\begin{tabular}{|c|c|c|c|c|c|c|c|}
\hline \multirow[t]{2}{*}{ Parameters } & \multirow{2}{*}{$\begin{array}{l}\text { Number } \\
\text { of study }\end{array}$} & \multicolumn{4}{|c|}{$\mathrm{a}_{\text {Egger's test }}$} & \multicolumn{2}{|c|}{$\mathrm{b}_{\text {Begg's test }}$} \\
\hline & & $\begin{array}{l}\text { Odds ratios } \\
\text { (OR)/ } \\
\text { Coe-efficient } \\
(\beta)(95 \% \mathrm{CI})\end{array}$ & $\begin{array}{c}\text { P- } \\
\text { values }\end{array}$ & $\begin{array}{l}\text { Bias (OR or } \\
\text { B) }(95 \% \mathrm{CI})\end{array}$ & $\begin{array}{c}\text { P- } \\
\text { values }\end{array}$ & $\begin{array}{c}\text { Adj. } \\
\text { Kendall's } \\
\text { score (P- } \\
\text { Q) }{ }^{C}\end{array}$ & $\begin{array}{c}\text { Continuity } \\
\text { corrected } \\
\text { test }\end{array}$ \\
\hline EIBF & 11 & $\begin{array}{c}\mathrm{OR}=0.99 \\
(0.89, \\
1.10)\end{array}$ & $\begin{array}{c}P= \\
0.885\end{array}$ & $\begin{array}{r}\mathrm{OR}=1.81 \\
(0.88 \\
3.72)\end{array}$ & $\begin{array}{c}P= \\
0.096\end{array}$ & $\begin{array}{r}13(\mathrm{Z}= \\
1.01, \mathrm{P}= \\
0.312)\end{array}$ & $\begin{array}{r}\mathrm{Z}=0.93 \\
(\mathrm{P}= \\
0.350)\end{array}$ \\
\hline EBF & 16 & $\begin{array}{r}\mathrm{OR}=0.94 \\
(0.81,1.09)\end{array}$ & $\begin{array}{c}P= \\
0.363\end{array}$ & $\begin{array}{r}\mathrm{OR}=4.94 \\
(1.51 \\
16.18)\end{array}$ & $\begin{array}{c}P= \\
0.012\end{array}$ & $\begin{array}{r}-18(\mathrm{Z}= \\
-0.81, \mathrm{P}= \\
0.417)\end{array}$ & $\begin{array}{r}\mathrm{Z}=0.77 \\
(\mathrm{P}= \\
0.444)\end{array}$ \\
\hline MDD & 17 & $\begin{array}{c}\beta=-0.83 \\
(-0.87 \\
-0.79)\end{array}$ & $\begin{array}{c}\mathrm{P}< \\
0.001\end{array}$ & $\begin{array}{r}\beta=0.83 \\
(0.80 \\
0.87)\end{array}$ & $\begin{array}{c}\mathrm{P}< \\
0.001\end{array}$ & $\begin{array}{r}134(\mathrm{Z}= \\
5.52, \mathrm{P}< \\
0.001)\end{array}$ & $\begin{array}{r}Z=5.48 \\
(P< \\
0.001)\end{array}$ \\
\hline MMF & 13 & $\begin{array}{r}\beta=-0.45 \\
(-0.57 \\
-0.33)\end{array}$ & $\begin{array}{c}\mathrm{P}< \\
0.001\end{array}$ & $\begin{array}{c}\beta=0.51 \\
(0.41 \\
0.61)\end{array}$ & $\begin{array}{c}\mathrm{P}< \\
0.001\end{array}$ & $\begin{array}{r}78(\mathrm{Z}= \\
4.76, \mathrm{P}< \\
0.001)\end{array}$ & $\begin{array}{r}\mathrm{Z}=4.70 \\
(\mathrm{P}< \\
0.001)\end{array}$ \\
\hline HAZ & 14 & $\begin{array}{r}\beta=-0.18 \\
(-0.75 \\
0.38)\end{array}$ & $\begin{array}{c}\mathrm{P}= \\
0.494\end{array}$ & $\begin{array}{c}\beta=-0.22 \\
(-12.35 \\
11.91)\end{array}$ & $\begin{array}{c}P= \\
0.969\end{array}$ & $\begin{array}{r}-17(\mathrm{Z}= \\
-0.93, \mathrm{P}= \\
0.352)\end{array}$ & $\begin{array}{r}\mathrm{Z}=0.88 \\
(\mathrm{P}= \\
0.381)\end{array}$ \\
\hline WHZ & 16 & $\begin{array}{r}\beta=0.08 \\
(-0.08 \\
0.23)\end{array}$ & $\begin{array}{c}P= \\
0.323\end{array}$ & $\begin{array}{r}\beta=-2.84 \\
(-6.52, \\
0.84)\end{array}$ & $\begin{array}{c}P= \\
0.120\end{array}$ & $\begin{array}{r}32(\mathrm{Z}= \\
-1.44, \mathrm{P}= \\
0.150)\end{array}$ & $\begin{array}{r}Z=1.40 \\
(P= \\
0.163)\end{array}$ \\
\hline WAZ & 16 & $\begin{array}{r}\beta=0.06 \\
(-0.15 \\
0.28) \\
\end{array}$ & $\begin{array}{c}\mathrm{P}= \\
0.532\end{array}$ & $\begin{array}{r}\beta=-3.01 \\
(-7.73 \\
1.72) \\
\end{array}$ & $\begin{array}{c}\mathrm{P}= \\
0.194\end{array}$ & $\begin{array}{r}-6(\mathrm{Z}= \\
-0.27, \mathrm{P}= \\
0.787) \\
\end{array}$ & $\begin{array}{r}\mathrm{Z}=0.23 \\
(\mathrm{P}= \\
0.822) \\
\end{array}$ \\
\hline
\end{tabular}

Note: $\mathrm{EIBF}=$ Early initiation of breastfeeding, $\mathrm{EBF}=$ Exclusive breastfeeding, MDD $=$ Minimum dietary diversity, MMF = Minimum meal frequency, HAZ = Height for age $z$ scores, $W H Z=$ Weight for height $z$-scores, $W A Z=$ Weight for age $z$-scores. ${ }^{\text {a }}$ Egger's test for small-study effects was performed in terms of regress standard normal deviate of effect estimate against its standard error, ${ }^{b} \mathrm{Begg}$ 's test was performed to detect publication bias for small-study effects, ${ }^{\mathrm{c}}$ Rank correlation between standardized effect estimate and its standard error.

Table 2. Stratified analysis of the effectiveness of interventions on infant and young child feeding (IYCF) practices and anthropometric outcomes 


\begin{tabular}{|c|c|c|c|c|}
\hline \multirow[t]{2}{*}{ Parameters } & \multicolumn{2}{|c|}{ Meta-regression } & \multicolumn{2}{|c|}{$\begin{array}{l}\text { Monte Carlo permutation test for meta- } \\
\text { regression }\end{array}$} \\
\hline & $\begin{array}{l}\text { Pooled estimate } \\
\text { (odds ratios, OR or } \\
\text { coefficient, } \beta) \\
(95 \% \mathrm{CI})\end{array}$ & $\begin{array}{l}\text { Probability } \\
\text { values } \\
\text { (P-values) }\end{array}$ & $\begin{array}{l}\text { Unadjusted } \\
\text { P-values }\end{array}$ & $\begin{array}{l}\text { Adjusted } \\
\text { P-values }\end{array}$ \\
\hline \multicolumn{5}{|l|}{ EIBF ( $\mathrm{n}=11$ studies) } \\
\hline $\begin{array}{l}\text { Number of study } \\
\text { participants }\end{array}$ & $\mathrm{OR}=1.31(1.22,1.41)$ & $<0.001$ & 0.025 & 0.109 \\
\hline Intervention duration & $\mathrm{OR}=1.12(1.03,1.29)$ & $<0.001$ & 0.067 & 0.074 \\
\hline Permutations & - & - & \multicolumn{2}{|c|}{1000} \\
\hline \multicolumn{5}{|l|}{ EBF ( $\mathrm{n}=16$ studies $)$} \\
\hline $\begin{array}{l}\text { Number of study } \\
\text { participants }\end{array}$ & $\mathrm{OR}=0.99(0.99,1.00)$ & 0.904 & 0.776 & 0.878 \\
\hline Intervention duration & $\mathrm{OR}=1.02(0.86,1.19)$ & 0.640 & 0.608 & 0.752 \\
\hline Permutations & - & - & \multicolumn{2}{|c|}{1000} \\
\hline \multicolumn{5}{|l|}{ MDD ( $\mathrm{n}=16$ studies $)$} \\
\hline $\begin{array}{l}\text { Number of study } \\
\text { participants }\end{array}$ & $\beta=0.002(-0.001,0.002)$ & 0.960 & 0.697 & 0.913 \\
\hline Intervention duration & $\beta=0.001(-0.046,0.048)$ & 0.981 & 0.865 & 0.982 \\
\hline Permutations & - & - & \multicolumn{2}{|c|}{1000} \\
\hline \multicolumn{5}{|l|}{ MMF ( $\mathrm{n}=12$ studies) } \\
\hline $\begin{array}{l}\text { Number of study } \\
\text { participants }\end{array}$ & $\beta=0.003(-0.051,0.053)$ & 0.958 & 0.626 & 0.847 \\
\hline \multirow{3}{*}{$\begin{array}{l}\text { Intervention duration } \\
\text { Permutations } \\
\text { HAZ ( } \mathrm{n}=14 \text { studies) }\end{array}$} & $\begin{array}{c}\beta=-0.005(-0.001 \\
0.001)\end{array}$ & 0.984 & 0.682 & 0.905 \\
\hline & - & - & \multicolumn{2}{|c|}{1000} \\
\hline & \multicolumn{4}{|c|}{ HAZ ( $\mathrm{n}=14$ studies) } \\
\hline $\begin{array}{l}\text { Number of study } \\
\text { participants }\end{array}$ & $\begin{array}{c}\beta=-0.018(-0.075 \\
0.038)\end{array}$ & 0.493 & 0.574 & 0.745 \\
\hline Intervention duration & $\beta=0.001(-0.001,0.002)$ & 0.638 & 0.607 & 0.853 \\
\hline Permutations & - & - & \multicolumn{2}{|c|}{1000} \\
\hline \multicolumn{5}{|l|}{ WHZ ( $\mathrm{n}=16$ studies) } \\
\hline $\begin{array}{l}\text { Number of study } \\
\text { participants }\end{array}$ & $\beta=-0.069(-0.009,0.023)$ & 0.372 & 0.447 & 0.520 \\
\hline Intervention duration & $\beta=-0.002(-0.008,0.006)$ & 0.576 & 0.408 & 0.766 \\
\hline Permutations & - & - & \multicolumn{2}{|c|}{1000} \\
\hline \multirow{4}{*}{$\begin{array}{l}\text { WAZ ( } \mathrm{n}=16 \text { studies) } \\
\text { Number of study } \\
\text { participants } \\
\text { Intervention duration } \\
\text { Permutations } \\
\end{array}$} & & & & \\
\hline & $\beta=0.001(-0.001,0.004)$ & 0.223 & 0.302 & 0.311 \\
\hline & $\beta=-0.01(-0.03,0.01)$ & 0.395 & 0.231 & 0.514 \\
\hline & - & - & \multicolumn{2}{|c|}{1000} \\
\hline
\end{tabular}

Note $: \mathrm{EIBF}=$ Early initiation of breastfeeding, $\mathrm{EBF}=$ Exclusive breastfeeding, $\mathrm{MDD}=$ Minimum dietary diversity, $\mathrm{MMF}=\mathrm{Minimum}$ meal frequency, HAZ = Height for age z-scores, WHZ = Weight for height z-scores, WAZ = Weight for age z-scores

\section{Figures}




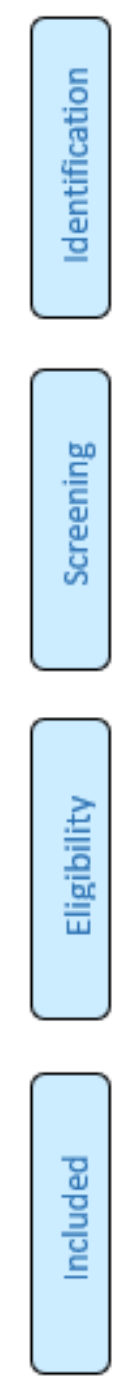

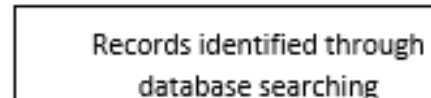

database searching $(n=1201)$
Additional records identified through other sources $(\mathrm{n}=33)$

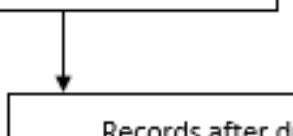

Records after duplicates removed

$$
\text { ( } n=867 \text { ) }
$$
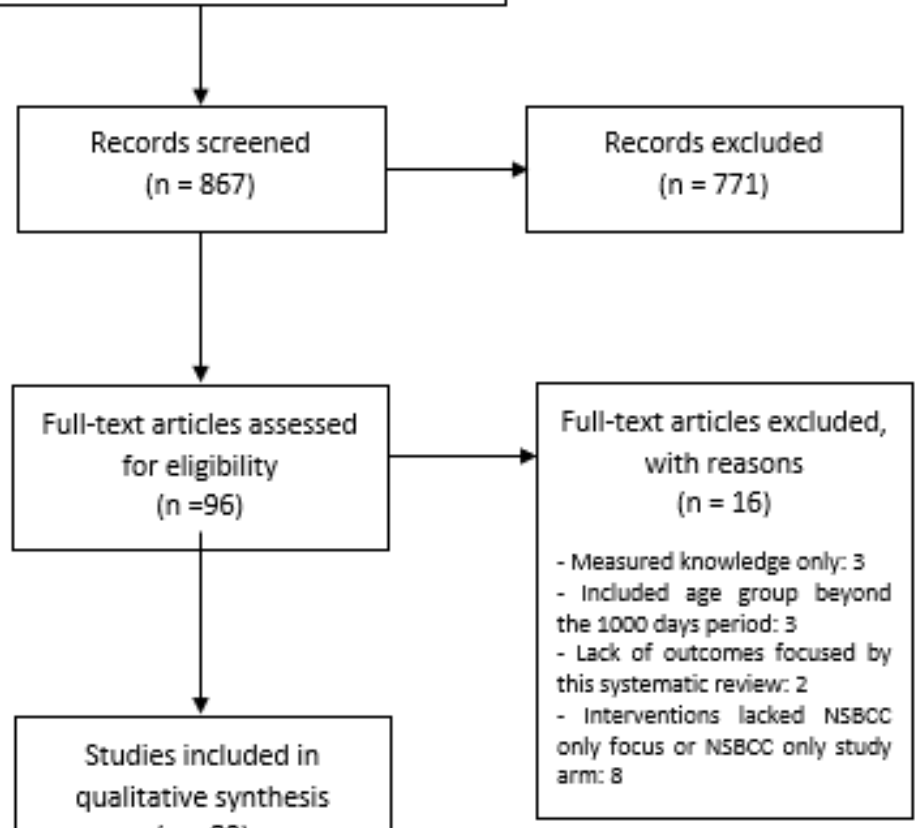

( $n=80$ )

Figure 1

PRISMA Flow Chart 

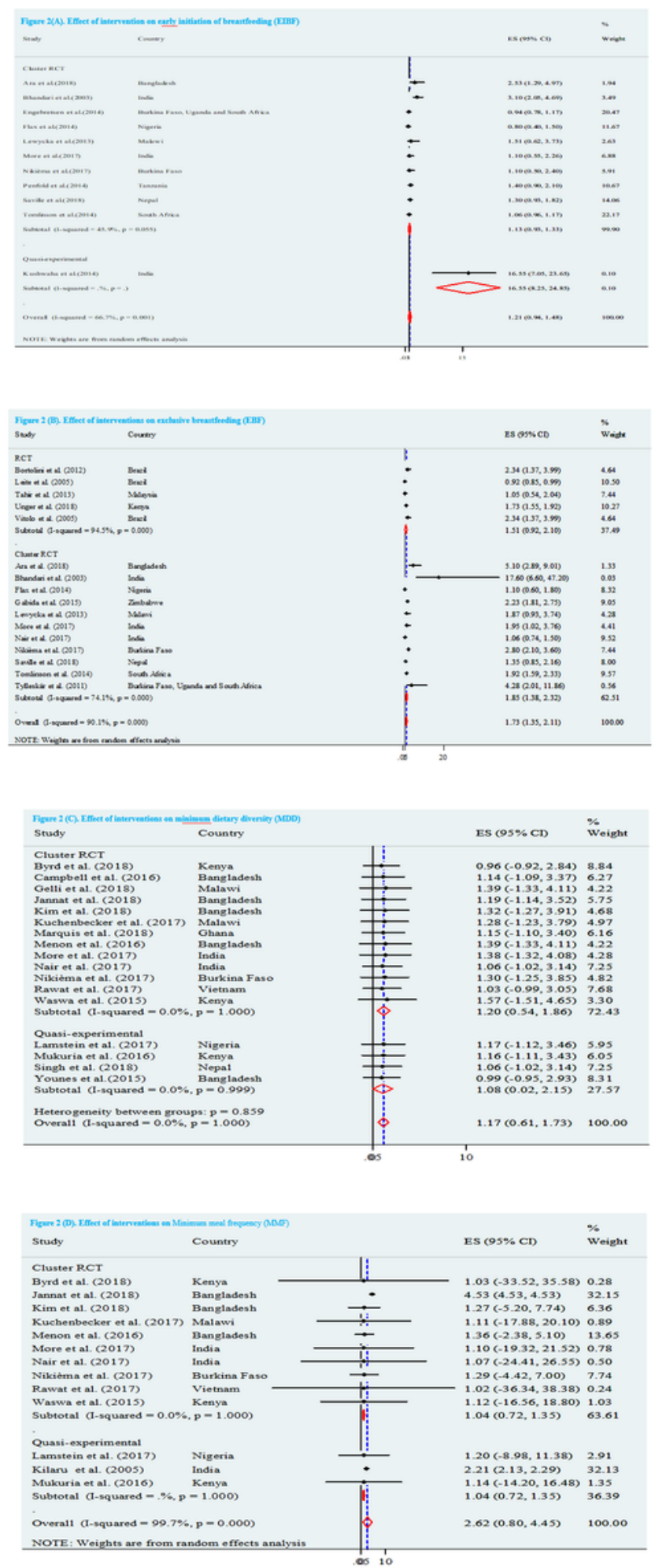

Figure 2

[See figure] 

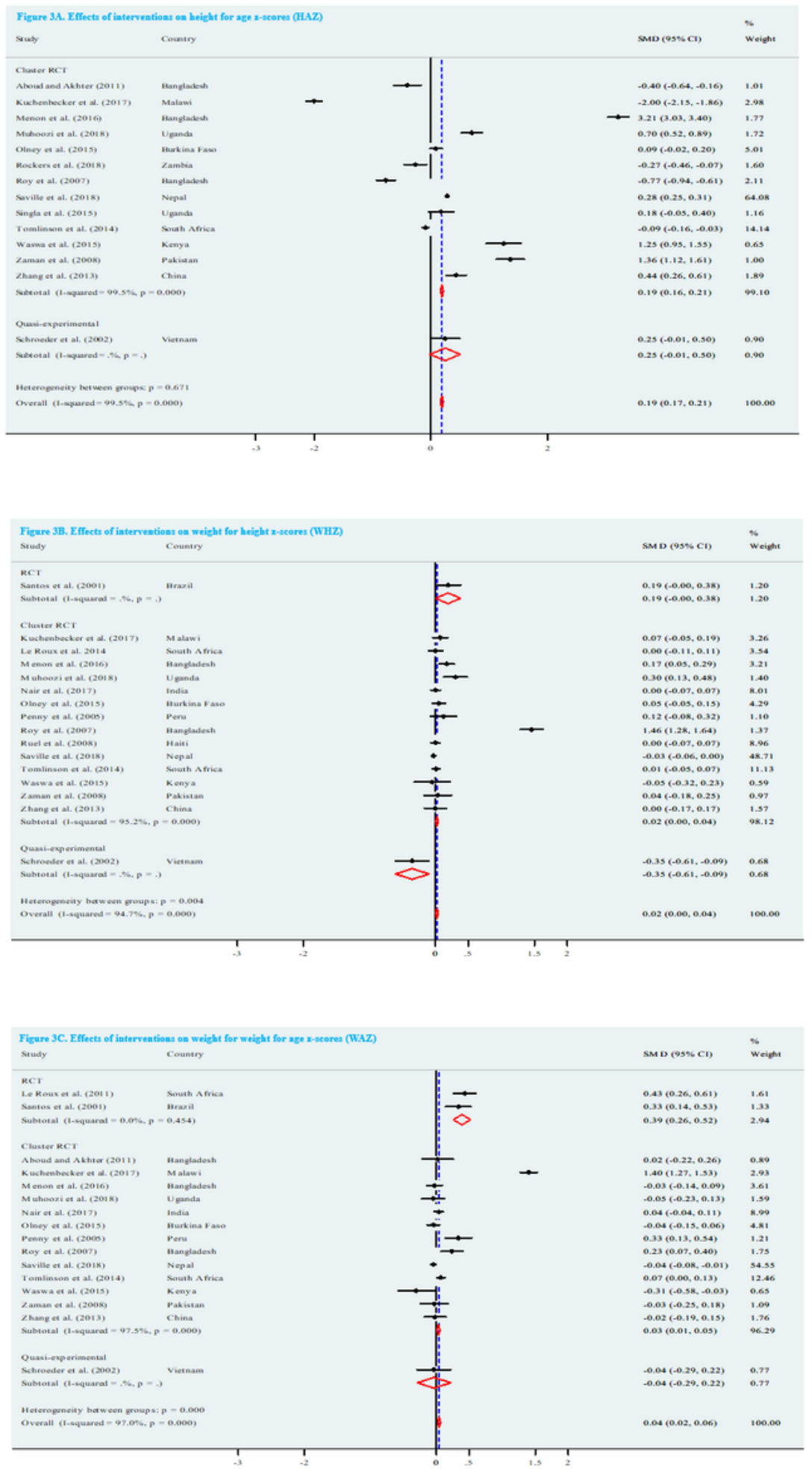

\section{Figure 3}

[See figure]

\section{Supplementary Files}

This is a list of supplementary files associated with this preprint. Click to download. 
- AppendixTables.docx

- AppendixFigureA1.pptx 